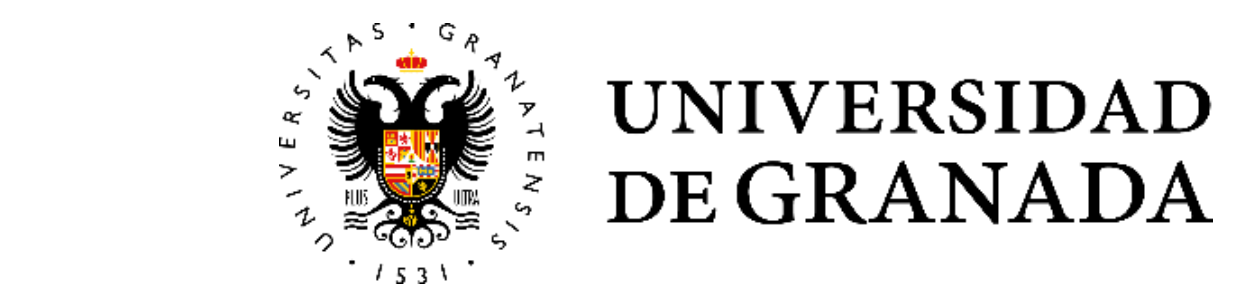

\title{
PROPAGACIÓN DE ONDAS SÍSMICAS EN UN ASTEROIDE
}

Trabajo Fin de Máster

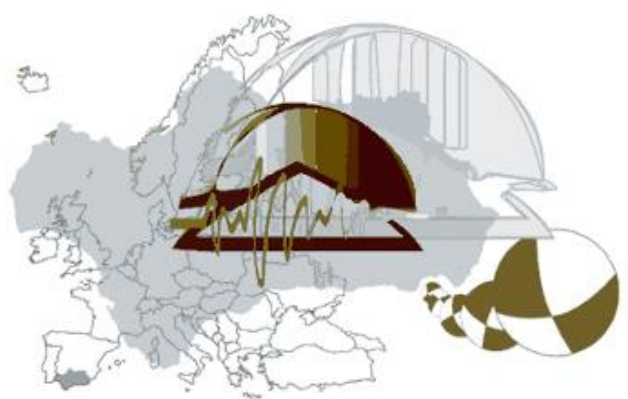

instituto anoaluz de geofísica

Hugo Latorre Cortés

Dirigido por los Dres. Daniel Stich \& René Duffard Curso 2019-2020 


\section{Contenido}

1. Introducción ........................................................................ 4

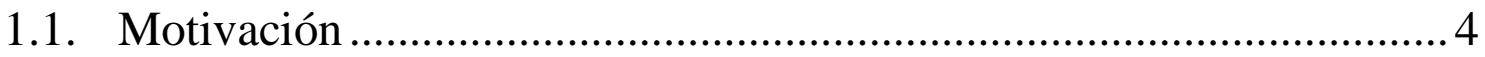

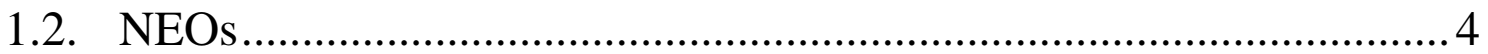

1.2.1. Las dos misiones Hayabusa (JAXA) y OSIRIS-Rex (NASA) ....................... 5

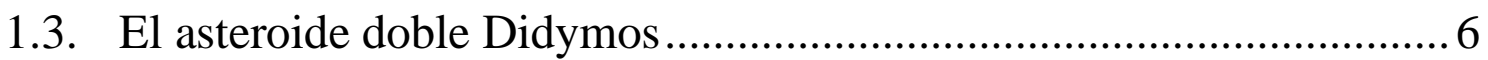

1.3.1. Misiones DART y Hera (NASA y ESA) ........................................................ 6

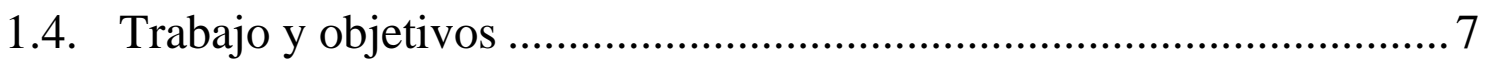

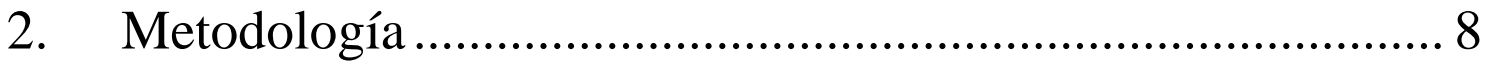

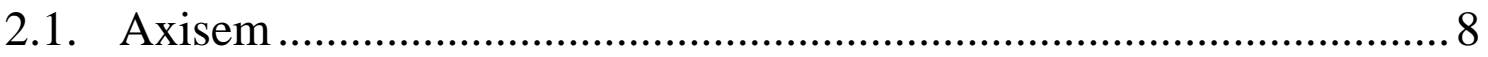

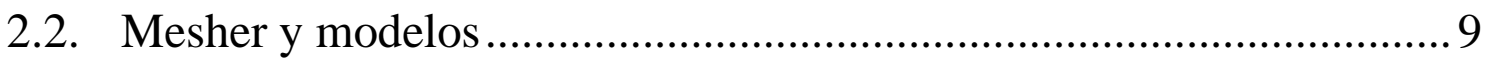

2.2.1. Parámetros del modelo ......................................................................... 9

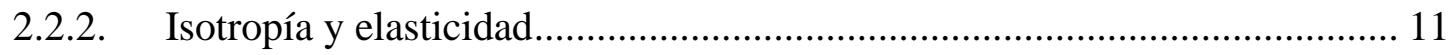

2.2.3. Parámetros del Mesher ............................................................................ 11

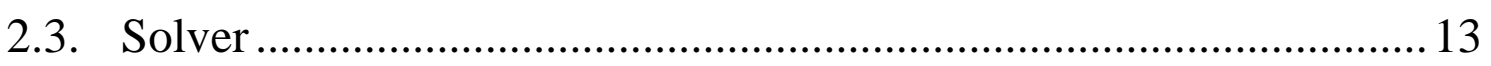

2.3.1. Modelado y parametrización de la fuente ……………………................... 13

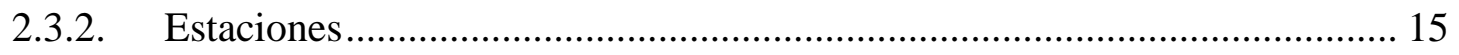

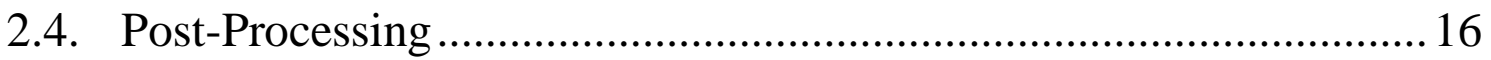

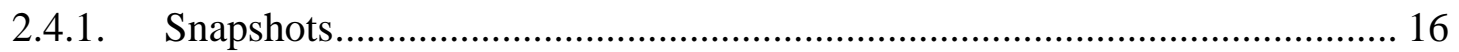

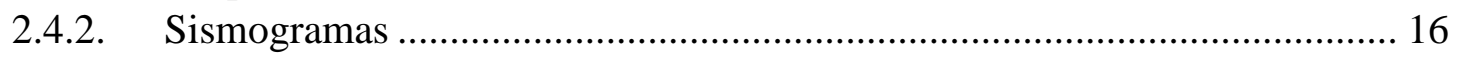

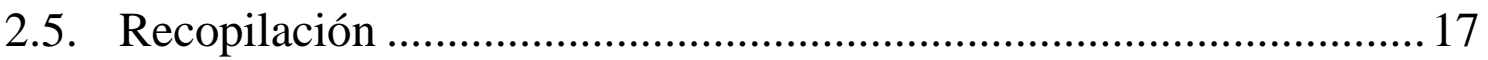

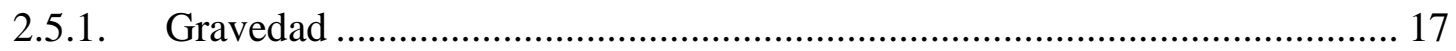

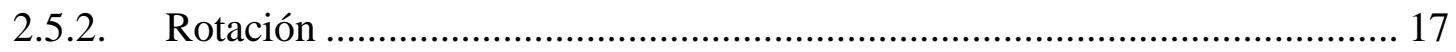

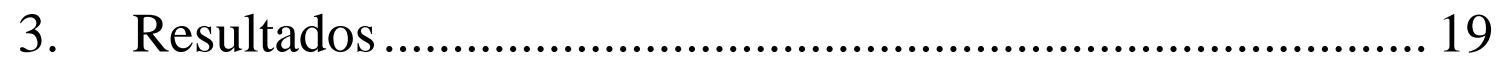

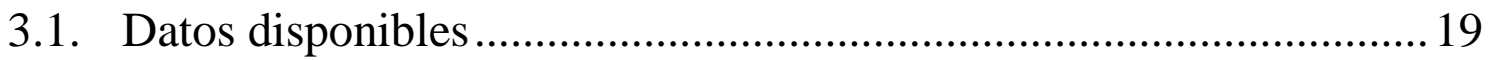

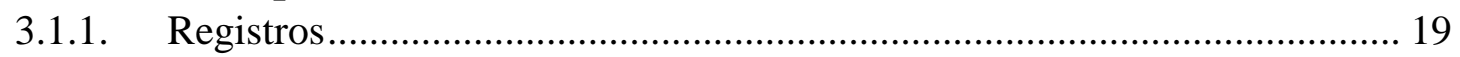

3.1.2. Snapshots e interpretación..................................................................... 22

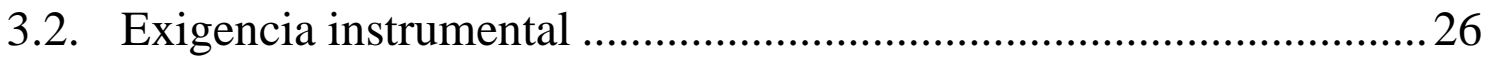

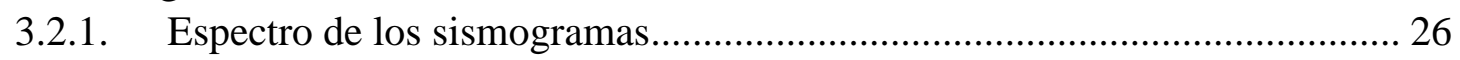

3.2.2. Frecuencia de muestreo ......................................................................... 27 


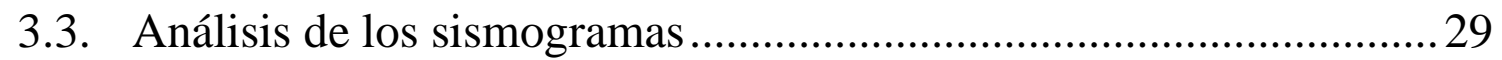

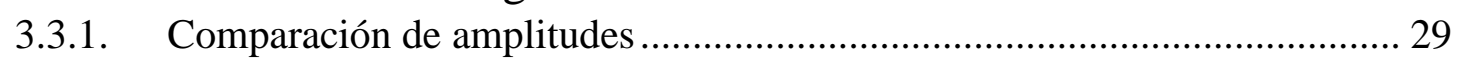

3.3.2. Aceleración y velocidad del suelo............................................................. 30

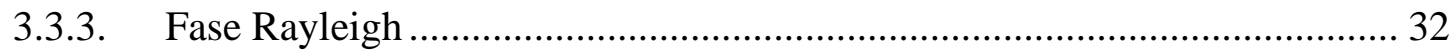

3.3.4. Primeras llegadas y justificación de la fuente ................................................ 34

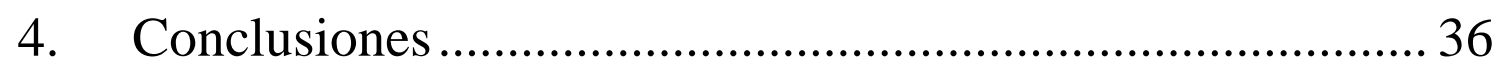

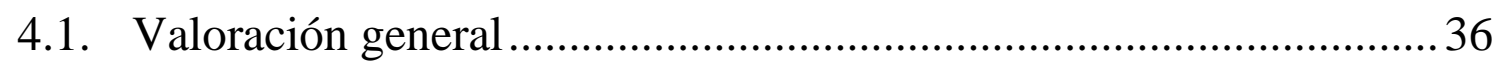

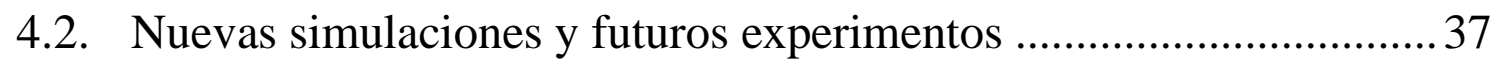

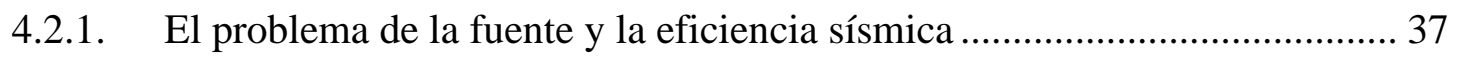

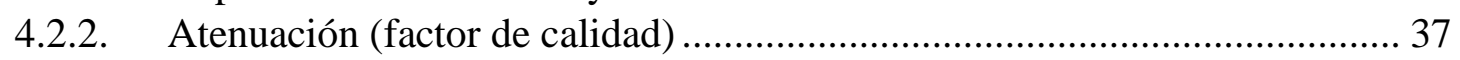

4.2.3. Cambios en el modelo de fondo ................................................................. 38

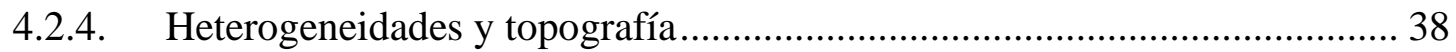

4.2.5. Colocación del instrumento........................................................................... 39

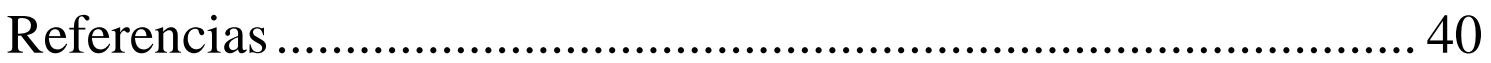




\section{Introducción}

\subsection{Motivación}

La sismología actual se centra en el estudio de la Tierra haciendo uso de extensas redes de estaciones sísmicas permanentes, además de un gran número de despliegues temporales. La investigación sísmica en otros cuerpos del Sistema Solar está muy limitada o es incluso inexistente en la mayoría de los casos.

Ejemplos de experimentos sísmicos fuera de la Tierra son la sísmica activa realizada durante los alunizajes del Programa Apolo (Cooper et al., 1974) y la red sísmica de cuatro estaciones que estuvo funcionando hasta 1977 y todavía proporciona resultados nuevos al aplicar distintas técnicas para revisar los registros (Nunn et al., 2020). Recientemente la misión InSight consiguió instalarse en Marte con éxito y empezó a tomar registros sísmicos con una única estación (Lognonné et al., 2019).

Lo que se plantea en este trabajo es la posibilidad de realizar este tipo de experimentos en asteroides y ver qué características y valor informativo podrían tener. Para ello se hará uso de herramientas y modelos que permitan estudiar este tema dentro de los límites que ofrece un trabajo de este tipo.

\subsection{NEOs}

Los NEOs (Near Earth Asteroids) son un grupo de asteroides cuyas órbitas los sitúan muy próximos a la Tierra. Ocasionalmente sus trayectorias coinciden con la Tierra y se produce un impacto si el objeto tiene el tamaño suficiente. Cuando el objeto es pequeño, la atmósfera lo desintegra antes de alcanzar la superficie. Los asteroides de mayor tamaño pertenecientes a este grupo son considerados como una potencial amenaza para la población humana.

El riesgo que suponen estos asteroides se evalúa en función de distintos parámetros y motiva su descubrimiento y monitorización (Chapman, 2004; Rumpf et al., 2017). Hay misiones en curso destinadas a estudiar la posibilidad de desviar estos objetos, aunque todavía no a gran escala (Cheng et al., 2012).

Otro aspecto relevante, aunque todavía no muy discutido fuera de entidades interesadas, es la prospección de minerales. La Luna ya se ha considerado como posible objetivo de explotación (Cecilia, 2019), mientras que la viabilidad en asteroides se ha planteado a nivel económico y tecnológico (Zacny et al., 2013), reconociendo que el valor científico de una extracción exitosa sería inmenso.

La clasificación de NEOs por tamaño aparece en la Fig 1.1 y se actualiza continuamente. Hay ya varias misiones que han visitado NEOs: Hayabusa, Hayabusa2 y OSIRIS-Rex, las dos últimas todavía en curso. La proximidad los hace más accesibles que otros grupos de asteroides y en un futuro se espera que siga habiendo misiones destinadas a estudiarlo. 


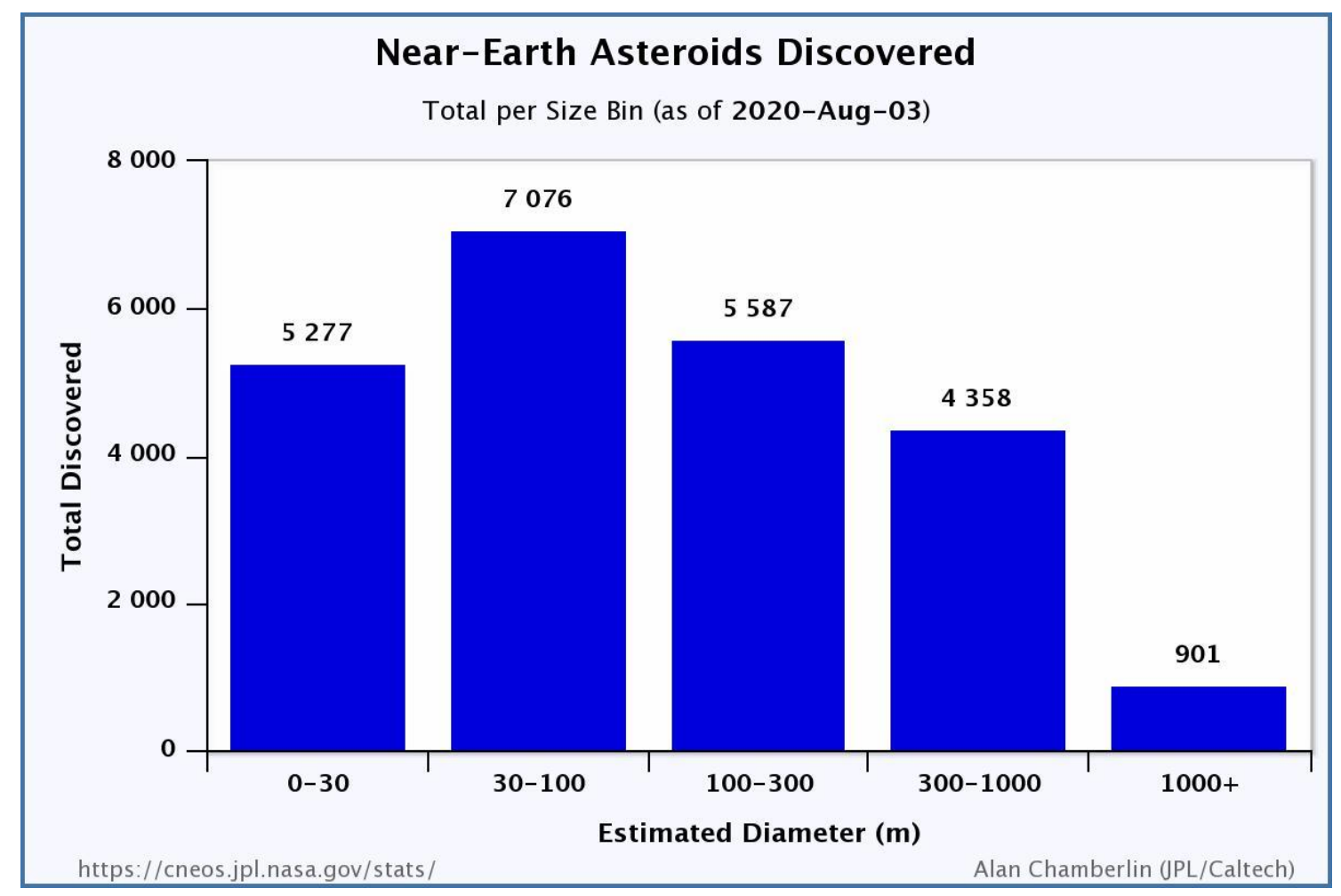

Figura 1.1. Histograma de NEOs por tamaños. La base de datos se actualiza constantemente. Fuente: https://cneos.jpl.nasa.gov/stats/size.html

A continuación, se presenta una breve descripción de cada una de las tres misiones que acaban de mencionarse. Después se centrará la atención en el asteroide y misión que inspiran este trabajo.

\subsubsection{Las dos misiones Hayabusa (JAXA) y OSIRIS-Rex (NASA)}

Hayabusa visitó el asteroide Itokawa y regresó con éxito a la Tierra trayendo muestras superficiales de regolito (capa superficial de material no consolidado que descansa sobre el material rocoso inalterado). La hipótesis sobre la estructura de estos objetos los consideraba pilas de escombros (rubble-piles) que quedaban sustentadas principalmente por su propia microgravedad. La misión Hayabusa obtuvo imágenes que confirmaron el aspecto que se pensaba que tendrían los objetos de este tipo. Una descripción de los rubble-pile se puede encontrar en (Walsh, 2018). Macroscópicamente, se describen con una macroporosidad elevada debido a la irregularidad de los fragmentos y una tensión de rotura prácticamente nula.

Hayabusa2 está actualmente en curso y entre sus objetivos, aparte de volver a traer muestras de vuelta como su predecesora, está el hacer impactar un proyectil contra la superficie del asteroide Ryugu y evaluar la zona de impacto. El impacto tuvo lugar y el cráter resultante fue encontrado y caracterizado (“"The Hayabusa Missions' with Seiji Sugita, University of Tokyo, Japan - ISSI”, 2020). 
La misión OSIRIS-REx en Bennu también recogerá y traerá muestras. Destaca el uso de un muelle de fuerza constante para tratar de caracterizar el regolito y ver si es posible inferir cualquier tipo de estratificación (Walsh, 2018). No se compara a un experimento sísmico convencional, pero es un primer paso de cara a tratar de caracterizar la superficie de un rubble-pile.

\subsection{El asteroide doble Didymos}

El asteroide Didymos va acompañado de un objeto secundario más pequeño que lo orbita, llamado comúnmente Didymoon. Al primero también se lo llama Didymain. La existencia de este segundo objeto se infirió a partir de medidas radiométricas, similar a cómo se descubren muchos exoplanetas. En la Tabla 1.1 se recogen algunos de los parámetros estimados de este asteroide doble. Didymoon es el objeto en el que se basarán los modelos propuestos en este trabajo.

Utilizar a Didymoon como referencia en este trabajo viene inspirado por una futura misión doble cuyo objetivo es estudiar el sistema y el tipo de experimentos que se van a realizar.

\subsubsection{Misiones DART y Hera (NASA y ESA)}

La misión DART (Double Asteroid Redirection Test) de la NASA llegará al asteroide doble y, a diferencia de otras misiones a NEOs, no regresará a la Tierra, sino que impactará contra Didymoon con el objetivo de cambiar su órbita (Adams et al., 2019). Esta reciente tendencia a hacer impactar proyectiles conocidos sobre asteroides es lo que lleva a plantear la posibilidad de incluir los experimentos sísmicos en el paquete de instrumentos de la misión. De esta manera se aportaría otra utilidad extra al impacto en forma de fuente activa.

Tabla 1.1. Algunos de los parámetros que se han estimado para ambos objetos. No se incluyen los errores porque en el contexto de este trabajo los valores son meramente orientativos. Didymoon tiene un tamaño típico para un NEO, mientras que Didymain es un NEO relativamente grande (ver Fig

1.1).Fuente: https://www.esa.int/Safety Security/Hera/Didymos facts figures

\begin{tabular}{|c|c|}
\hline Parámetro & Valor \\
\hline Densidad Didymain & $2146 \mathrm{~kg} / \mathrm{m}^{3}$ \\
\hline Diámetro Didymain & $775 \mathrm{~m}$ \\
\hline Periodo rotacional Didymain & $2,26 \mathrm{~h}$ \\
\hline Distancia entre centros & $1,18 \mathrm{~km}$ \\
\hline Diámetro Didymoon & $163 \mathrm{~m}$ \\
\hline Periodo orbital Didymoon & $11,92 \mathrm{~h}$ \\
\hline
\end{tabular}


Esta misión forma parte de una misión conjunta, AIDA (Asteroid Impact and Deflection Assessment), en la que colaboran la NASA y la ESA. La ESA no recibió el presupuesto necesario para lanzar AIM (Asteroid Impact Monitoring) y llegar antes que DART para caracterizar y monitorizar el asteroide (Cheng et al., 2018), por lo que finalmente será Hera la misión por parte de la ESA.

Hera llegará después de haberse producido el impacto, por lo que se pierde la posibilidad de poder tomar buenas medidas previas al cambio de órbita que se predice para Didymoon. A diferencia del experimento que realizó la JAXA en Ryugu, aquí no se soltará un proyectil acelerado para luego buscar el lugar de impacto, sino que DART se acercará e interceptará Didymoon tal cual llegue al asteroide (impacto a $6 \mathrm{~km} / \mathrm{s}$ visto desde Didymoon). No será hasta la llegada de Hera cuando se podrá evaluar el resultado.

\subsection{Trabajo y objetivos}

Visto el contexto que rodea al trabajo, se va a presentar una herramienta con la que generar y evaluar modelos sísmicos. La finalidad es ver si sería posible obtener registros sísmicos en un asteroide de los que extraer información con la que poder caracterizar el objeto en cuestión. Esto pasa por hacer una hipótesis simple sobre la estructura y el tipo de fuente a utilizar para luego comparar registros y extraer conclusiones. 


\section{Metodología}

\subsection{Axisem}

En la actualidad, la sismología fuera de la Tierra cuenta con muchas limitaciones. Una alternativa que puede ayudar a comprobar una hipótesis o interpretar futuros datos experimentales es la generación de sismogramas sintéticos con los que poder visualizar registros sísmicos en un modelo teórico. Esto ya se hace con modelos de la Tierra y por tanto se extiende el método a otros cuerpos del Sistema Solar, aunque todavía no haya registros sísmicos disponibles con la excepción de la Luna y, recientemente, Marte.

Una opción adecuada a este trabajo es Axisem (Nissen-Meyer et al., 2014), un código abierto que simula campos de ondas que se propagan por medios axisimétricos. Axisem usa el método de elementos espectrales para aproximar numéricamente la propagación de ondas sísmicas en presencia de heterogeneidades. Para ello, divide el medio de propagación en subdominios pequeños, análogo al método de elementos finitos. El método de elementos espectrales es de orden superior y utiliza una base de polinomios de Legendre para expandir la solución en cada elemento, siendo el método más avanzado para simulaciones precisas en sismología planetaria en la actualidad (Chaljub et al., 2007). En el caso especial de AxiSEM, los cuerpos tienen siempre simetría esférica y las variaciones de parámetros son axisimétricas tales que el problema a resolver numéricamente se vuelve bidimensional mientras que la tercera dimensión espacial se calcula analíticamente. Con este método se consigue simplificar el problema original, pero también lo vuelve menos realista cuando la topografía tiene una presencia importante en el cómputo total de las distancias. La forma irregular de los asteroides no puede tenerse en cuenta con este método. El código está pensado para utilizarse con modelos de la Tierra y modelos externos de otros planetas o satélites con un cierto tamaño. No obstante, los propios desarrolladores aseguran que puede funcionar a escalas centimétricas y eso es lo que se hará en este trabajo.

La característica más relevante de este programa es su reducido consumo de recursos computacionales en comparación a otros que calculan soluciones numéricas en 3D. Un ordenador personal es más que suficiente para hacerlo funcionar y obtener soluciones en un tiempo razonable. Esto se consigue haciendo uso de las librerías MPI (Message Passing Interface) para ejecutar código en paralelo, mientras que el programa como tal está escrito en Fortran90. Una vez compilado con éxito, el programa no requerirá de nuevas compilaciones salvo cambios mayores. Por lo general, cambiar parámetros básicos o el modelo de fondo no requiere la recompilación de todo el programa.

El programa está probado en sistemas tipo UNIX, particularmente Linux. En este trabajo se utiliza Ubuntu con las librerías imprescindibles que especifica el manual correspondiente. Herramientas no imprescindibles para hacer funcionar el programa, pero útiles para visualizar los datos, son Gnuplot para visualizar los sismogramas (plots) y Paraview para visualizar la malla de elementos del modelo, así como para producir instantáneas del campo de ondas (snapshots). El equipo empleado para las simulaciones 
es de 4 procesadores y 6GB de memoria RAM, suficiente para hacer funcionar el programa y trabajar con los modelos que van a proponerse.

El programa está dividido en otros tres programas que funcionan de manera independiente: Mesher, Solver y Post-Processing, cada uno con su función descrita a continuación. La asignación de parámetros también se lleva a cabo durante la descripción.

\subsection{Mesher y modelos}

Este es el primero de los tres programas y su función es crear una malla (mesh) válida que pueda ser utilizada por el Solver. Requiere de un modelo (background model) de entrada que se guarda en un fichero de texto. Los parámetros básicos que necesariamente deben estar incluidos son la densidad del material y las velocidades sísmicas $\mathrm{P}$ y $\mathrm{S}$, junto con los radios correspondientes a los que se aplican los valores. Las discontinuidades se fuerzan con dos líneas del mismo radio y los parámetros correspondientes. En cualquier otro caso el programa interpolará para completar el modelo.

Existe la posibilidad de utilizar modelos anisótropos y anelásticos, pero no se hará en este trabajo. Los modelos aquí planteados incluirán los parámetros correspondientes en los modelos para evitar problemas al generar el mesh, aunque luego no se activen en la simulación.

\subsubsection{Parámetros del modelo}

El asteroide de referencia para construir los modelos es Didymoon, el cuerpo secundario de Didymos. Las principales referencias para construir el modelo son Murdoch et al., 2017 y Garcia et al., 2015. El primer artículo propone una serie de modelos para Didymoon de los cuales hay dos que Axisem puede manejar razonablemente. Se deja fuera la opción con huecos (i.e. reflectores) aleatorios en el interior porque es difícil de implementar bien con Axisem, además de estar poco probada. La estructura con capa superficial de $1 \mathrm{~m}$ puede dar problemas a nivel computacional por cómo funciona el Mesher y no es compatible a nivel físico con la fuente que se va a emplear. Esto se aclarará más adelante.

Se considera un diámetro de 200m y dos posibles estructuras internas, la primera con una capa de regolito de $10 \mathrm{~m}$ y un núcleo más consolidado, mientras que la segunda es enteramente monolítica con las propiedades del núcleo consolidado. El parámetro de referencia a utilizar es la densidad media del cuerpo principal de Didymos (ver Tabla 1.1), y se asume que en Didymoon tiene un valor similar.

Asignando esta densidad al núcleo $\left(2146 \mathrm{~kg} / \mathrm{m}^{3}\right)$ se puede estimar la velocidad de las ondas P utilizando la relación de Gardner (Gardner et al., 1974).

$$
\rho=\alpha \cdot V_{p}^{\beta} \Rightarrow V_{p}=\left(\frac{\rho}{\alpha}\right)^{(1 / \beta)}
$$


Esta ecuación es una buena opción cuando solo se conoce la densidad media. Dos valores que ajustan bien bastantes observaciones de campo y laboratorio son $\alpha=0,31$ y $\beta$ $=0,25$. Para determinar la velocidad de las ondas $\mathrm{S}$ se pueden emplear las ecuaciones que relacionan las velocidades sísmicas con los parámetros geofísicos.

$$
\begin{gathered}
\mathrm{V}_{\mathrm{p}}=\sqrt{\frac{\mathrm{E}}{\rho} \sqrt{\frac{(1-v)}{(1+v)(1-2 v)}}} \\
\mathrm{V}_{\mathrm{s}}=\sqrt{\frac{\mathrm{E}}{\rho} \frac{1}{\sqrt{2(1+v)}}}
\end{gathered}
$$

Estas ecuaciones son muy útiles porque dan una relación entre las velocidades de onda P y S como función del coeficiente de Poisson (v).

$$
\mathrm{V}_{\mathrm{s}}=\mathrm{V}_{\mathrm{p}} \sqrt{\frac{1}{2} \frac{(1-2 v)}{(1-v)}}
$$

Dando un valor típico de $v=0,25$ (sólido de Poisson) al coeficiente (Murdoch et al., 2017; Quillen et al., 2019) se obtiene la velocidad para las ondas S (Murdoch et al., 2017 tiene un error en la relación y olvida la raíz).

$$
\mathrm{V}_{\mathrm{s}}(v=0,25)=0,58 \cdot \mathrm{V}_{\mathrm{p}}
$$

Los parámetros del núcleo son $\rho=2146 \mathrm{~kg} / \mathrm{m}^{3} ; \mathrm{V}_{\mathrm{p}}=2297 \mathrm{~m} / \mathrm{s} ; \mathrm{V}_{\mathrm{s}}=1326 \mathrm{~m} / \mathrm{s}$ en ambos modelos. Las propriedades del regolito no podrán conocerse hasta que se haya observado la superficie (misiones DART y Hera). Una forma de caracterizar el regolito en un NEO, mientras no haya datos sísmicos, es utilizar los resultados de la sísmica activa que se realizó durante el Apolo 17 (Cooper 1974) en la Luna.

Asumiendo unas propiedades como las del mega regolito lunar (Garcia et al., 2015; Murdoch et al., 2017), la capa quedaría caracterizada con los parámetros $\rho=1500 \mathrm{~kg} / \mathrm{m}^{3}$, $\mathrm{V}_{\mathrm{p}}=900 \mathrm{~m} / \mathrm{s}$ y $\mathrm{V}_{\mathrm{s}}=400 \mathrm{~m} / \mathrm{s}$, en claro contraste con el núcleo. El mega regolito lunar es el nombre que se da a la capa fracturada que queda por debajo del regolito superficial, y su origen está en los impactos grandes sobre la Luna.

Un ejemplo de fichero de texto que contiene un modelo se muestra en la Fig 2.1. y la Fig 2.2 muestra los perfiles de densidad y modelos de velocidad de ambos modelos.

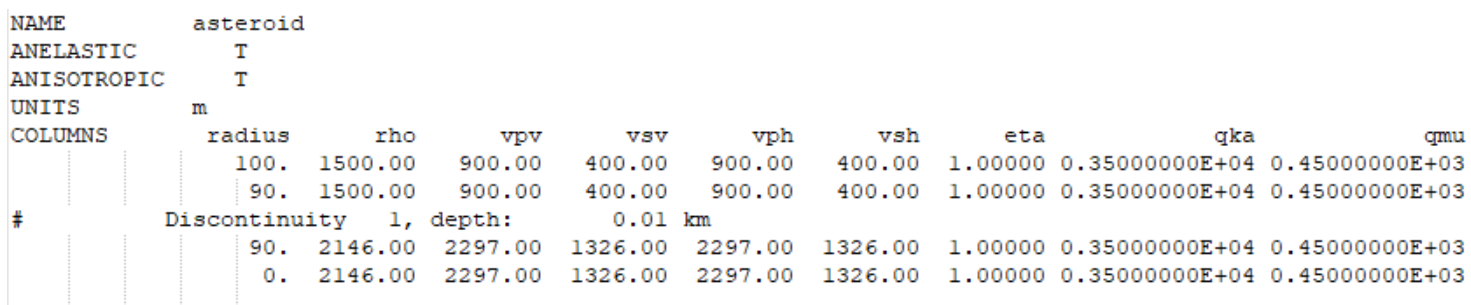

Figura 2.1. Plantilla para modelos externos de Axisem. El modelo corresponde al que tiene 10m de regolito. Las columnas, por orden: radio, densidad, velocidad $\mathrm{P}$ y $\mathrm{S}$ verticales, factores de calidad $\mathrm{P}$ y $\mathrm{S}$, velocidades $\mathrm{P}$ y S horizontales, parámetro de anisotropía. 

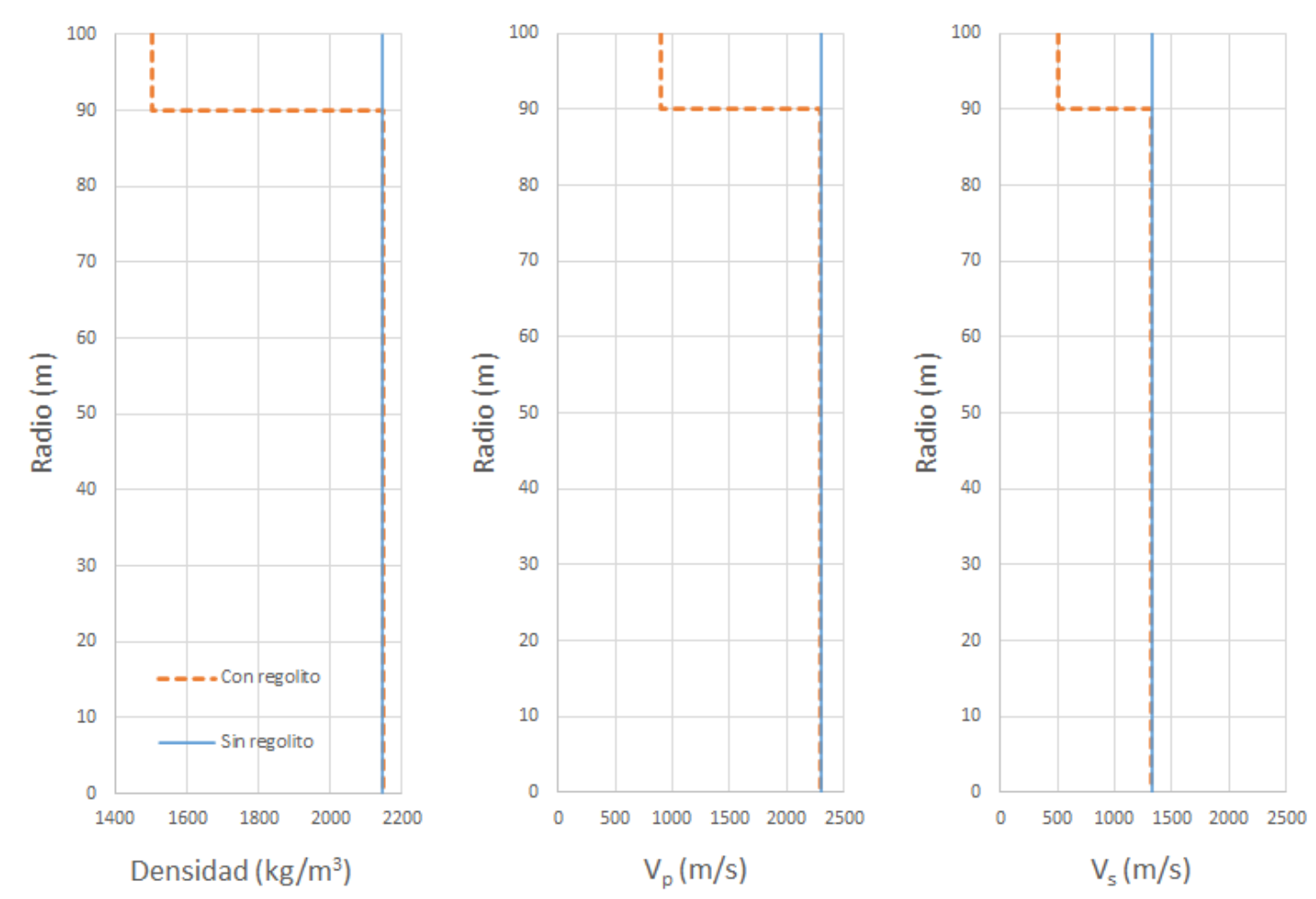

Figura 2.2. Perfiles de densidad y modelos de velocidad en los casos con y sin regolito. La línea naranja discontinua representa el modelo con regolito y la línea azul continua el modelo sin regolito. El eje del parámetro correspondiente está escalado para ver cómodamente la diferencia. En el caso de las velocidades el escalado es el mismo para apreciar bien las diferencias.

\subsubsection{Isotropía y elasticidad}

Un modelo isótropo y elástico es una buena aproximación para simular un campo de ondas en este tipo de cuerpos (Martin et al., 2008; Quillen et al., 2019). Las anisotropías deberían ser grandes para poder apreciarse en distancias tan cortas y todavía no se cuenta con datos experimentales. La elasticidad no es algo obvio y la superficie de un asteroide podría ser bastante anelástica (Quillen et al., 2019). Aquí se opta por simplificar el problema dado que ya se está simplificando bastante al haber ignorado la topografía.

\subsubsection{Parámetros del Mesher}

Hay tres parámetros con los que se controla la generación del mesh: número de procesadores, periodo central y niveles de coarsening, donde se pueden fusionar elementos para variar el espaciado de la malla entre capas. Asignando los cuatro procesadores disponibles con el equipo de simulación se divide el mesh en cuatro partes que el Solver resuelve con cuatro procesos funcionando en paralelo.

El periodo central determinará la cantidad de puntos del mesh dado que el Mesher va estableciendo una cierta cantidad de puntos por longitud de onda. Las frecuencias que pueden resolverse están afectadas por el tamaño, en puntos, del mesh. Los niveles de 
coarsening son una forma de mantener una cierta regularidad en el número de puntos por longitud de onda duplicando el número de puntos para compensar la variación de la longitud del arco con el radio. Es también una forma de compensar el aumento de la velocidad con la profundidad (la longitud de onda se calcula con el periodo central y la velocidad). Se consigue así un modelo computacional más eficiente al calcular la solución.

El objetivo es conseguir un mesh de unos 40.000 elementos para asegurar una buena resolución y convergencia en la solución. La Fig 2.3 es un ejemplo de cómo se generan los niveles de coarsening en los dos modelos aquí planteados y la Tabla 2.1 recoge los parámetros y características computacionales de los modelos. Se debe evitar que los niveles de coarsening se generen en la superficie, por lo que una corteza de $1 \mathrm{~m}$ los dejaría demasiado próximos y podría conducir a errores en el Solver.

Tabla 2.1. Características de los mesh construidos. El doble nivel de coarsening en el modelo con regolito y permite conectar bien el núcleo con la corteza. El número de elementos es similar en ambos casos y los periodos dominantes se han elegido para cumplir esta condición. Al resolver para una fuente arbitraria bastante más larga que estos periodos se compensa la diferencia en términos absolutos de resolución de frecuencias.

\begin{tabular}{l|cc}
\hline \multicolumn{1}{c}{ Con regolito } & Sin regolito \\
\hline Periodo dominante & $0,0018 \mathrm{~s}$ & $0,0012 \mathrm{~s}$ \\
Niveles de coarsening & 2 & 1 \\
Radios de coarsening & $89 \mathrm{~m}, 88 \mathrm{~m}$ & $77 \mathrm{~m}$ \\
$\mathbf{N}^{\mathbf{0}}$ procesadores & 4 & 4 \\
$\mathbf{N}^{\mathbf{0}}$ elementos en el $\boldsymbol{m e s h}$ & 42.240 & 40.736 \\
\hline
\end{tabular}

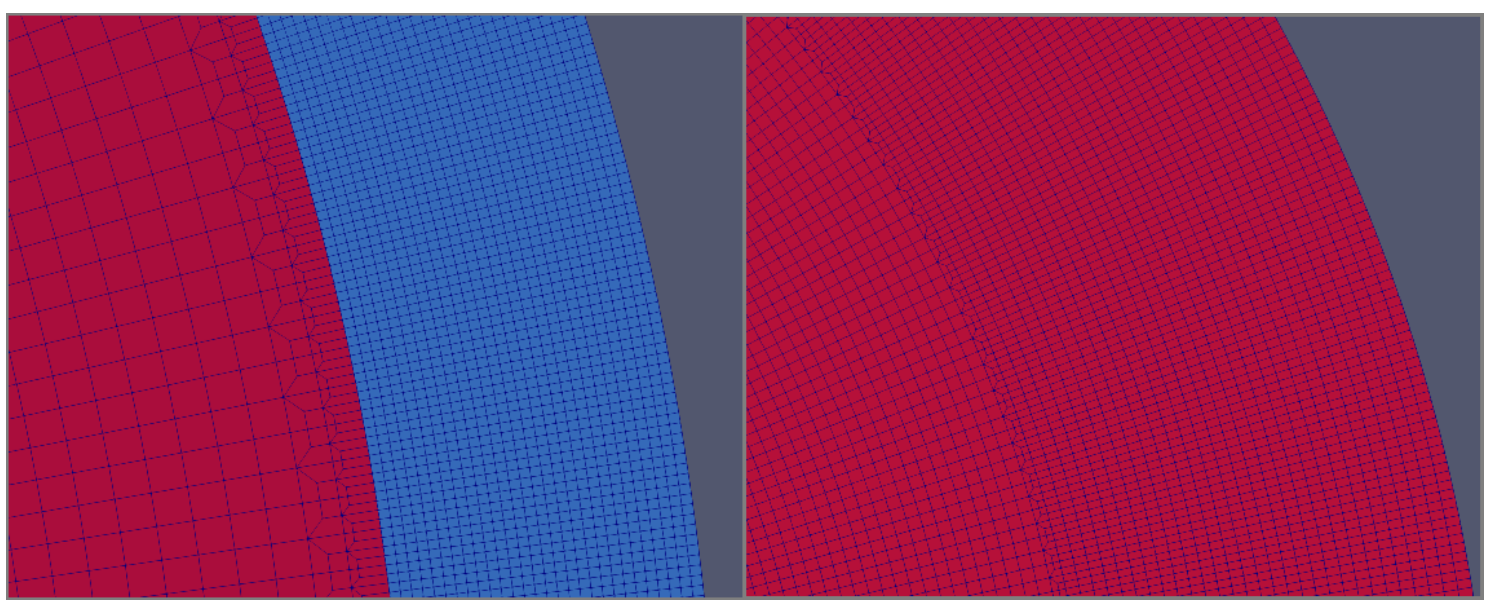

Figura 2.3. Ejemplos de coarsening aplicados a una discontinuidad para compensar la variación de velocidad y a una capa homogénea para compensar la variación de la longitud del arco. Los vértices que se ven en la estructura son los puntos del mesh. El aumento de resolución es considerable y conviene utilizar esta la herramienta si es posible. Axisem calcula automáticamente dónde duplicar puntos, y debe evitarse que se genere uno de estos niveles en la superficie ya que conduce a errores numéricos importantes. 


\subsection{Solver}

El segundo programa es el que se encarga de realizar la simulación propiamente dicha. Aquí se dan parámetros como el tipo de simulación (elementos del tensor de momentos a calcular), duración, algoritmo de integración, modelo de fondo, fuente y estaciones.

El muestreo y la longitud del sismograma son parámetros importantes para determinar el tiempo que dura la simulación. Para elemento pequeños y periodos centrales bajos, el salto temporal debe ser muy corto para lograr estabilidad numérica en la simulación y se encarece el coste computacional. Aquí es importante notar cómo cambian las escalas temporales debido a las distancias. Las velocidades en Didymoon se parecen a valores en la Tierra, pero las llegadas en comparación son prácticamente instantáneas a lo largo de toda la superficie y la apreción y separación de fases requiere una resolución temporal alta.

Por ejemplo, el tiempo que tarda la onda $\mathrm{P}$ en atravesar todo el modelo es $\mathrm{t}_{\mathrm{p}}=$ $\mathrm{D} / \mathrm{V}_{\mathrm{p}}$ donde $\mathrm{D}$ es el diámetro. En los modelos aquí considerados $\mathrm{t}_{\mathrm{p}} \sim 0,09 \mathrm{~s}$ y en adelante para las fases superficiales, que contrasta con los tiempos de llegada telesísmicos en la Tierra (del orden de minutos). Se elige una longitud de 5 s para los sismogramas con la intención de conseguir, si es posible, fases estacionarias.

La atenuación se puede ignorar desde el Solver aunque el modelo de fondo tenga los parámetros asignados. Se guardará un snapshot del campo de ondas cada $0.005 \mathrm{~s}$, acumulando un total de 1000 snapshots por simulación. El algoritmo de integración es Sympletic de cuarto orden para mitigar el "inflamiento" de la señal y quede inutilizable debido a la propagación y amplificación de ruido numérico. La Fig 2.4 es un ejemplo de señal inutilizable obtenida durante las pruebas del programa.

\subsubsection{Modelado y parametrización de la fuente}

La fuente sísmica en un asteroide es un problema muy complejo que puede merecer por sí solo un trabajo o incluso una tesis completa. Se opta entonces por utilizar parámetros ya calculados en artículos que discuten el modelado de impactos. El problema requiere, en esencia, calcular la magnitud de una fuerza vertical aplicada sobre la superficie asumiendo un impacto perpendicular. Axisem cuenta con la opción de simular fuerzas básicas en lugar de componentes del tensor de momentos, pero no implementa una rutina para sumarlas en el post procesado y obtener sismogramas.

La alternativa, que sí está completamente implementada con una rutina de post procesado, es utilizar una explosión. El tensor de momentos de una explosión ideal es diagonal con los tres elementos del mismo valor. Axisem necesita hacer una simulación para cada elemento independiente del tensor completo que se quiera simular, por lo que una explosión solo requiere de una única simulación que calcule el momento correspondiente. 


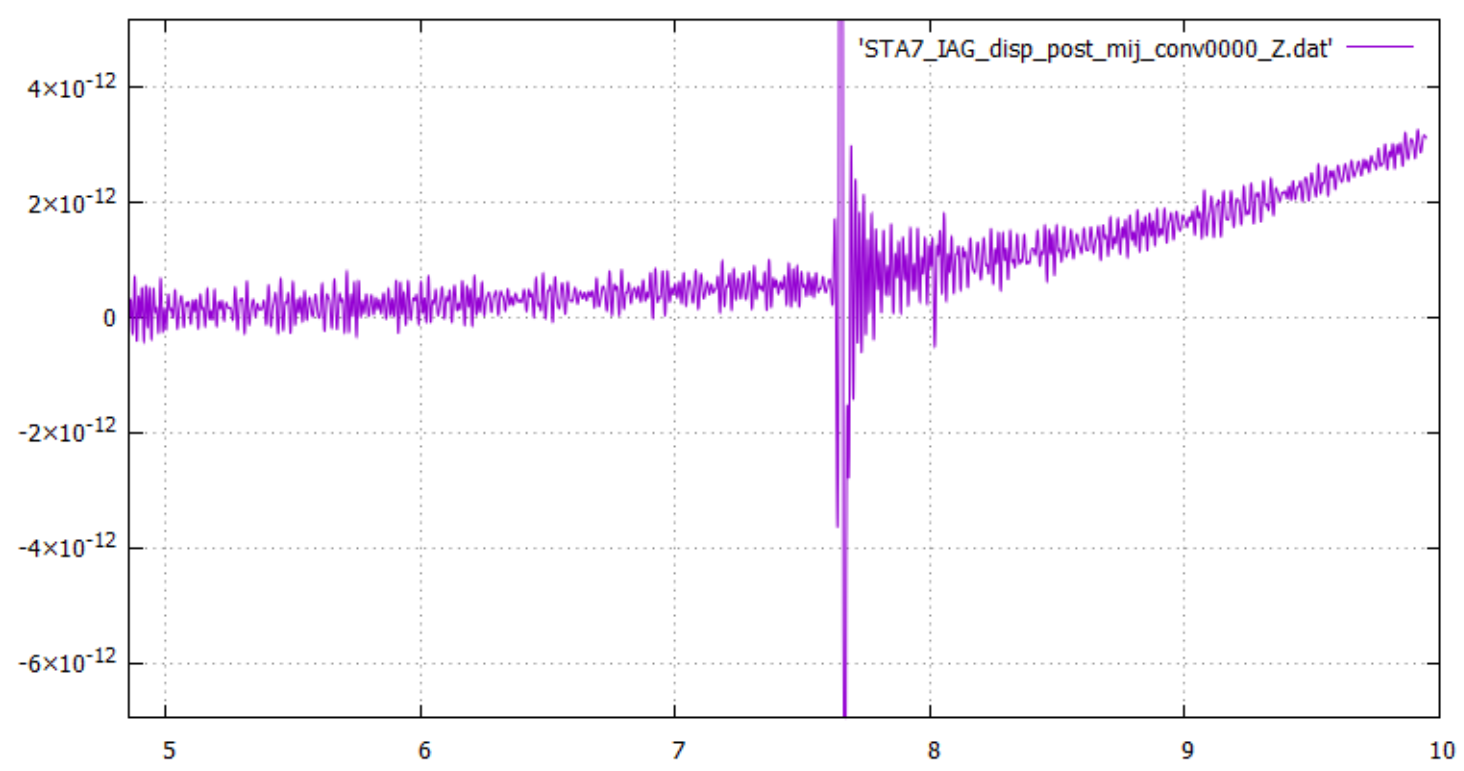

Figura 2.4. Ejemplo de un sismograma de prueba "inflado" con ruido numérico. Aparece una tendencia exponencial que se suma a la señal y la vuelve inutilizable. El eje de abscisas corresponde al tiempo en segundos mientras que el eje de ordenadas corresponde a la velocidad del suelo en $\mathrm{m} / \mathrm{s}$. Téngase en cuenta que el modelo arbitrario de prueba ya era pequeño para comprobar la utilidad del código con modelos mucho más pequeños que los terrestres. El algoritmo utilizado era Newmark de segundo orden, sustituido por Sympletic de cuarto orden en las simulaciones finales para garantizar la convergencia.

El tensor completo se suma en el post procesado para obtener los sismogramas. Los impactos y explosiones son fuentes parecidas para un experimento de este tipo y se caracterizan por tiempos de llegada, amplitudes máximas y anchuras de pulso similares (Walker and Huebner, 2004). El campo de ondas acaba siendo lo suficientemente parecido pese a utilizar una fuente isótropa que solo radia ondas $\mathrm{P}$, ya que también se generan ondas $\mathrm{S}$ y Rayleigh por la interacción con la superficie libre.

Los parámetros finales se eligen tomando Garcia et al., 2015 como referencia. La magnitud de la fuente queda en $3 \cdot 10^{4} \mathrm{Nm}$ teniendo en cuenta el tamaño de los modelos aquí manejados. La duración de la fuente será de $10 \mathrm{~ms}(100 \mathrm{~Hz})$ para facilitar el análisis de los resultados. Se tiene en cuenta que $\lambda_{\mathrm{p}}=\mathrm{V}_{\mathrm{p}} / v$ siendo $\lambda_{\mathrm{p}}(v=100 \mathrm{~Hz})=9 \mathrm{~m}$ la longitud de las ondas $\mathrm{P}$ en el regolito, suficiente para resolver la capa. La magnitud y la duración de la fuente determinan las amplitudes máximas de las fases (los pulsos cortos concentran más la energía para una misma magnitud). Se ve también por qué, al usar esta fuente, no tendría sentido considerar una capa de $1 \mathrm{~m}$ en el modelo al ser físicamente irresoluble.

La fuente estará situada en el polo Norte del modelo por conveniencia a la hora de conseguir que funcione el programa (todos los puntos son equivalentes cuando hay simetría esférica sin rotación). Se coloca a $50 \mathrm{~cm}$ de profundidad para garantizar que queda bien acoplada dentro del modelo computacional. Axisem traslada la fuente al punto del mesh más cercano y la corrección ofrecida apenas llega a los $10 \mathrm{~cm}$ (acaba quedando a unos $40 \mathrm{~cm}$ de profundidad). 
El último parámetro a considerar es la forma del pulso. Para evitar posibles fallos del Solver, es conveniente simular una fuente con el periodo de la red (el mínimo posible) y hacer la convolución pertinente en el post procesado. Esto es absolutamente necesario para conseguir snapshots sin ruido numérico, mientras que la convolución con una fuente arbitraria se debe hacer con una fuente delta de Dirac que viene específicamente implementada para ello. La delta de Dirac inutiliza los snapshots con ruido numérico que se elimina al hacer la convolución con una fuente gaussiana de la duración deseada (siempre mayor que el periodo dominante del mesh, evidentemente). En total hacen falta cuatro simulaciones para obtener todos los datos, dos por cada modelo.

\subsubsection{Estaciones}

Cualquier estación única que se coloque se traslada automáticamente al punto superficial del mesh más cercano, y a cada una se le asocia un nombre, una red, una latitud y una longitud. Axisem utiliza ficheros de texto con formato estandarizado e ignora los parámetros de altura y profundidad. Teniendo esto en cuenta, lo más relevante en una simulación de este tipo es la distancia a la fuente sobre la superficie (la fuente es también esencialmente superficial). Se coloca una estación cada 10 grados de arco hasta llegar a la antípoda de la fuente (polo Sur). La Fig 2.5 muestra el esquema final sobre la sección correspondiente de la esfera.

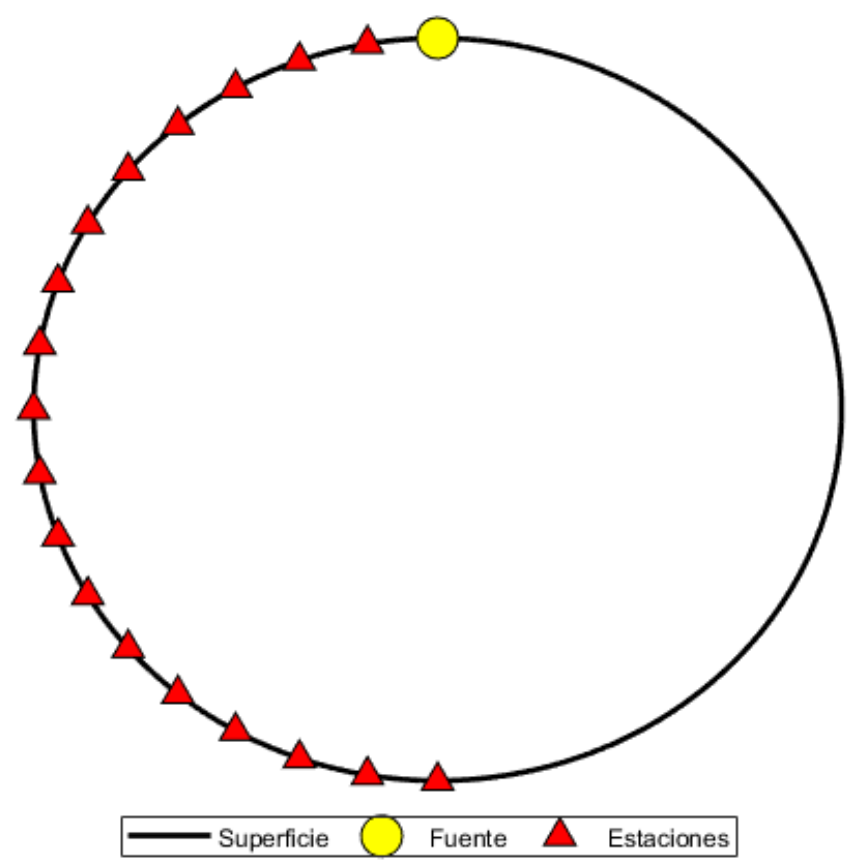

Figura 2.5. Distribución de estaciones sobre el modelo junto con la fuente. Hay un total de 18 estaciones disponibles. Por simetría, no es necesario colocar estaciones en el lado opuesto ya que el registro es idéntico. 


\subsection{Post-Processing}

El Post-Processing es una potente herramienta con la que extraer datos en forma de snapshots y sismogramas de las simulaciones realizadas. En particular, resulta útil el poder obtener sismogramas para duraciones y funciones de fuente diferentes sin tener que repetir la parte más costosa de la simulación.

\subsubsection{Snapshots}

Los snapshots son instantáneas del campo de ondas tomadas cada cierto tiempo. Cada snap se guarda en un archivo de extensión .vtk que se puede visualizar con Paraview. Cortando media esfera se puede ver el campo de ondas que se propaga por el interior.

La paleta no viene por defecto y debe crearse de manera que se vea claramente el contraste entre los frentes de ondas y el fondo del modelo. Se renderizan 1000 imágenes por modelo, correspondientes a los instantes en que el Solver ha guardado los valores del campo de ondas.

\subsubsection{Sismogramas}

Los sismogramas se obtienen como ficheros de texto que contienen dos columnas (tiempo, velocidad/aceleración) y se pueden representar con cualquier programa capaz de leer o importar datos tabulados. Gnuplot, MATLAB, Excel, SciDAVis, etc. son todos opciones adecuadas. Sus herramientas también son adecuadas para el análisis. Se puede optar también por utilizar programas pensados para uso sismológico como SAC y Seisan.

Los sismogramas que pueden obtenerse con las simulaciones realizadas son de velocidad y aceleración, con una fuente temporal correspondiente a un pulso gaussiano de duración arbitraria (recordar que debe ser mayor que el periodo del mesh). Aquí es necesario utilizar las simulaciones donde la función temporal de la fuente es una delta de Dirac, ya que la convolución de una función arbitraria con una delta de Dirac es la propia función y por tanto permite usar funciones temporales arbitrarias.

Los sismogramas que se obtienen al hacer la convolución con una gaussiana son de velocidad, o de aceleración si se utiliza la derivada de la gaussiana (estas dos funciones son las únicas implementadas en el post procesado). Obtener sismogramas de desplazamiento requiere utilizar una función temporal Heaviside (integral de una delta de Dirac) cuya convolución con una gaussiana devuelve un sismograma de desplazamiento. No se hará en este trabajo, pero merece la pena mencionar que la opción viene implementada en el Solver.

Hay tres componentes por estación, de los cuales solo $\mathrm{N}$ y Z son útiles en este caso, dado que la tercera componente $\mathrm{E}$ es nula al no haber ondas $\mathrm{S}$ polarizadas transversalmente (SH). La fuente utilizada es isótropa y no genera este tipo de ondas. Los modelos $2 \mathrm{D}$ axisimétricos tampoco pueden generarlas en las reflexiones y refracciones. 


\subsection{Recopilación}

De las cuatro simulaciones en total, se realizan dos con cada modelo. La diferencia entre las dos simulaciones de un mismo modelo es el tipo de fuente que utiliza el Solver. Para que los snapshots sean utilizables es necesario emplear una gaussiana. Para poder dar una duración arbitraria a la fuente es necesario hacer uso de la delta de Dirac específicamente implementada para ello, que inutiliza los snapshots con ruido numérico.

El experimento consiste entonces en simular los primeros $5 \mathrm{~s}$ del campo de ondas que se propaga en ambos modelos con una fuente explosiva de $3 \cdot 10^{4} \mathrm{Nm}$ y $10 \mathrm{~ms}$ colocada en la superficie, registrando el resultado con 18 estaciones separadas cada 10 grados de arco hasta la antípoda.

Axisem no tiene en cuenta la gravedad ni la rotación en sus modelos. En el caso aquí presentado es justificable no tener en cuenta estos efectos.

\subsubsection{Gravedad}

La gravedad en la superficie puede calcularse a partir de la masa total en cuerpos simétricamente esféricos donde la densidad depende únicamente del radio.

$$
M=\iiint \rho(r) d V=4 \pi \int_{0}^{R} \rho(r) \cdot r^{2} d r
$$

El radio de los modelos es $\mathrm{R}=100 \mathrm{~m}$ y su densidad $\rho=2146 \mathrm{~kg} / \mathrm{m}^{3}$ teniendo en cuenta que en los últimos $10 \mathrm{~m}$ del modelo con regolito $\rho=1500 \mathrm{~kg} / \mathrm{m}^{3}$. Resolviendo se tiene que las masas totales son $\mathrm{M}_{\mathrm{m}}=8,99 \cdot 10^{9} \mathrm{~kg}$ en el modelo sin regolito y $\mathrm{M}_{\mathrm{r}}=8,26 \cdot 10^{9}$ $\mathrm{kg}$ en el modelo con regolito.

La gravedad en la superficie del modelo es entonces

$$
\mathrm{g}=\mathrm{G} \frac{\mathrm{M}}{\mathrm{R}^{2}}
$$

y se tiene que $\mathrm{g}_{\mathrm{m}}=6,00 \cdot 10^{-5} \mathrm{~m} / \mathrm{s}^{2}$ sin regolito y $\mathrm{g}_{\mathrm{r}}=5,51 \cdot 10^{-5} \mathrm{~m} / \mathrm{s}^{2}$ con regolito. Dirección obviamente hacia el centro del modelo. Son seis órdenes de magnitud menos que la Tierra, por lo que el efecto es negligible y se aplica la teoría clásica de ondas convencional. No obstante, el cálculo resultará de utilidad más adelante al ver los resultados.

\subsubsection{Rotación}

La rotación tampoco tiene un efecto relevante en este problema. Asumiendo que Didymoon tiene resonancia 1:1 en sus periodos de rotación y traslación, le costaría 11,92h completar una revolución. Le cuesta un poco menos que a la Tierra dar media revolución, un periodo muy largo relativamente hablando si se tienen en cuenta los tamaños. 
La velocidad angular de rotación es $\omega=1,46 \cdot 10^{-4} \mathrm{rad} / \mathrm{s}$. En los $5 \mathrm{~s}$ que se están simulando, el cuerpo giraría $\varphi(5 \mathrm{~s})=7,32 \cdot 10^{-4} \mathrm{rad}$ que equivalen a poco más de $7 \mathrm{~cm}$ en la superficie. A efectos prácticos el cuerpo no cambia de orientación y es estacionario. 


\section{Resultados}

\subsection{Datos disponibles}

El paquete de datos disponible es el siguiente:

Snapshots del campo de ondas tomados cada 0,005s hasta 5s, un total 1000 .

$>$ Sismogramas vertical y horizontal de velocidad en 18 estaciones ( $100 \mathrm{~Hz}$ fuente).

$>$ Sismogramas vertical y horizontal de aceleración en 18 estaciones ( $100 \mathrm{~Hz}$ fuente).

$>$ Sismogramas vertical y horizontal de velocidad en 18 estaciones (periodo mesh).

La cantidad de datos corresponde a lo que se extrae para cada modelo, y por lo tanto el volumen total de datos es el doble. Los sismogramas generados para una fuente de duración igual al periodo del mesh no son particularmente útiles, pero Axisem los genera siempre que se procesen los resultados de una simulación, incluso cuando solo interesan los snapshots (para los snapshots existe la opción de no generarlos, aunque se hayan guardado con el Solver).

En los sismogramas de 5s puede apreciarse ruido numérico que infla la señal, en mayor o menor medida, en algunas estaciones. El modelo sin regolito está más afectado al propagar más rápido el campo de ondas por la superficie. Esto no es especialmente problemático dado que el ruido notable comienza cuando la fase superficial más lenta e intensa ya ha completado entre dos y tres vueltas al modelo. Los registros serían aptos para aplicar técnicas de sísmica activa, no tanto para analizar modos normales. Cabe destacar que los registros correspondientes a la antípoda de la fuente están bastante menos afectados por el ruido.

\subsubsection{Registros}

Los registros (sismogramas) se pueden representar en función de la distancia a la fuente y normalizados respecto a su propio máximo para una primera inspección. Más adelante se puede seleccionar un intervalo temporal de interés y normalizar respecto a una cantidad común para apreciar los cambios de amplitud con la polaridad y la dispersión. La atenuación también es muy importante pero aquí no se ha considerado.

Los registros del modelo sin regolito (Fig. 3.1) presentan tiempos de llegada ligeramente más cortos que los registros del modelo que sí tiene la corteza de regolito (Fig 3.2). La diferencia fundamental está en las fases superficiales, que se propagan exclusivamente por el regolito lento. Las rectas que describen indican que se propagan a velocidad constante (lo esperado en estos modelos) y el sentido de la pendiente indica si la onda se propaga en sentido horario (pendiente negativa) o antihorario (pendiente positiva). Son dos pulsos simétricos que interfieren constructivamente en la antípoda.

Esta representación solo permite apreciar la forma general y seguir algunas fases. Compararlos más a fondo requiere utilizar las amplitudes sin normalizar (o normalizadas a un valor común) y centrarse en intervalos temporales concretos. 

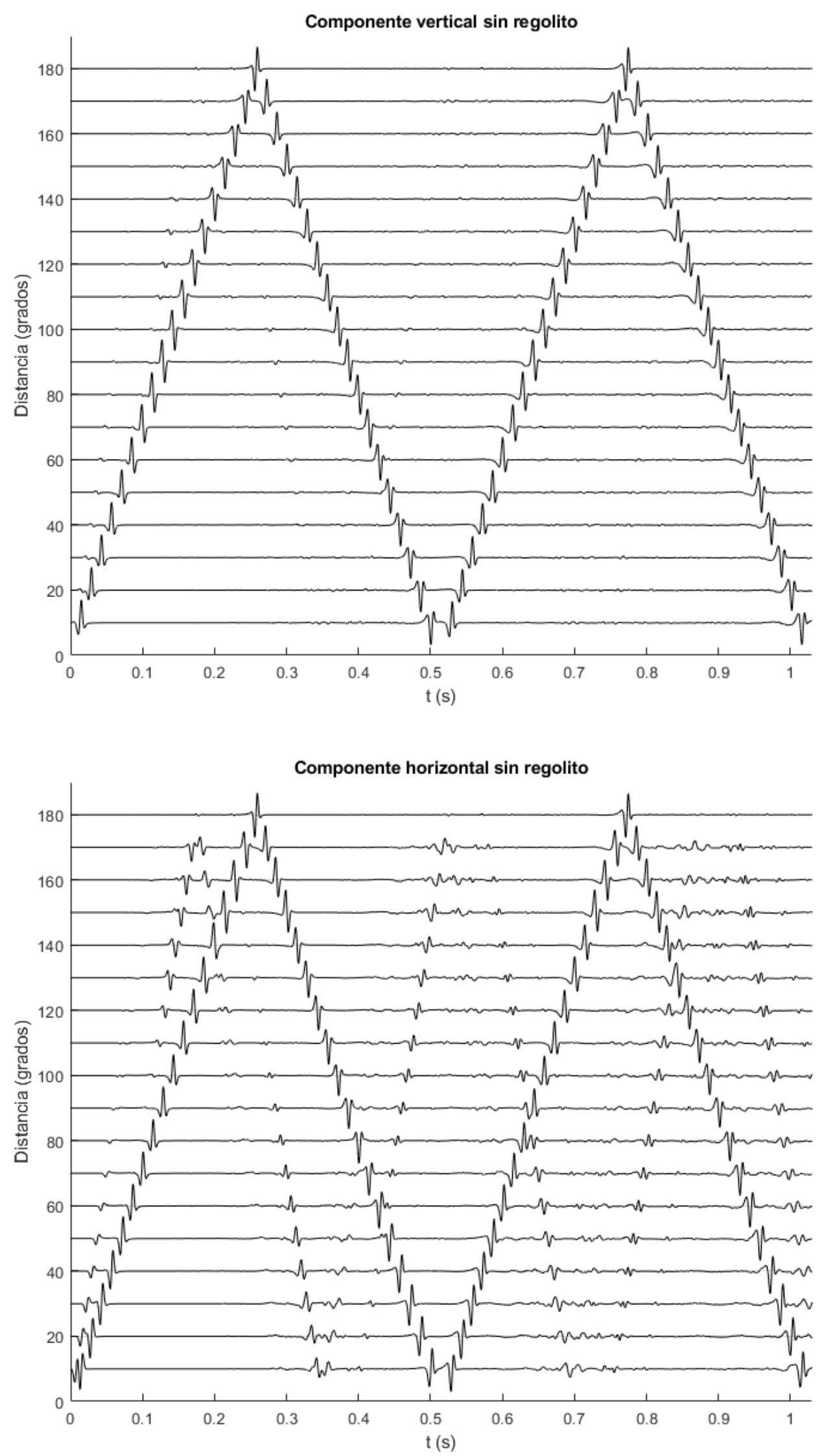

Figura 3.1. Componentes vertical y horizontal de los registros en el modelo sin regolito, normalizados a su respectiva máxima amplitud. Fuente de $100 \mathrm{~Hz}$. 

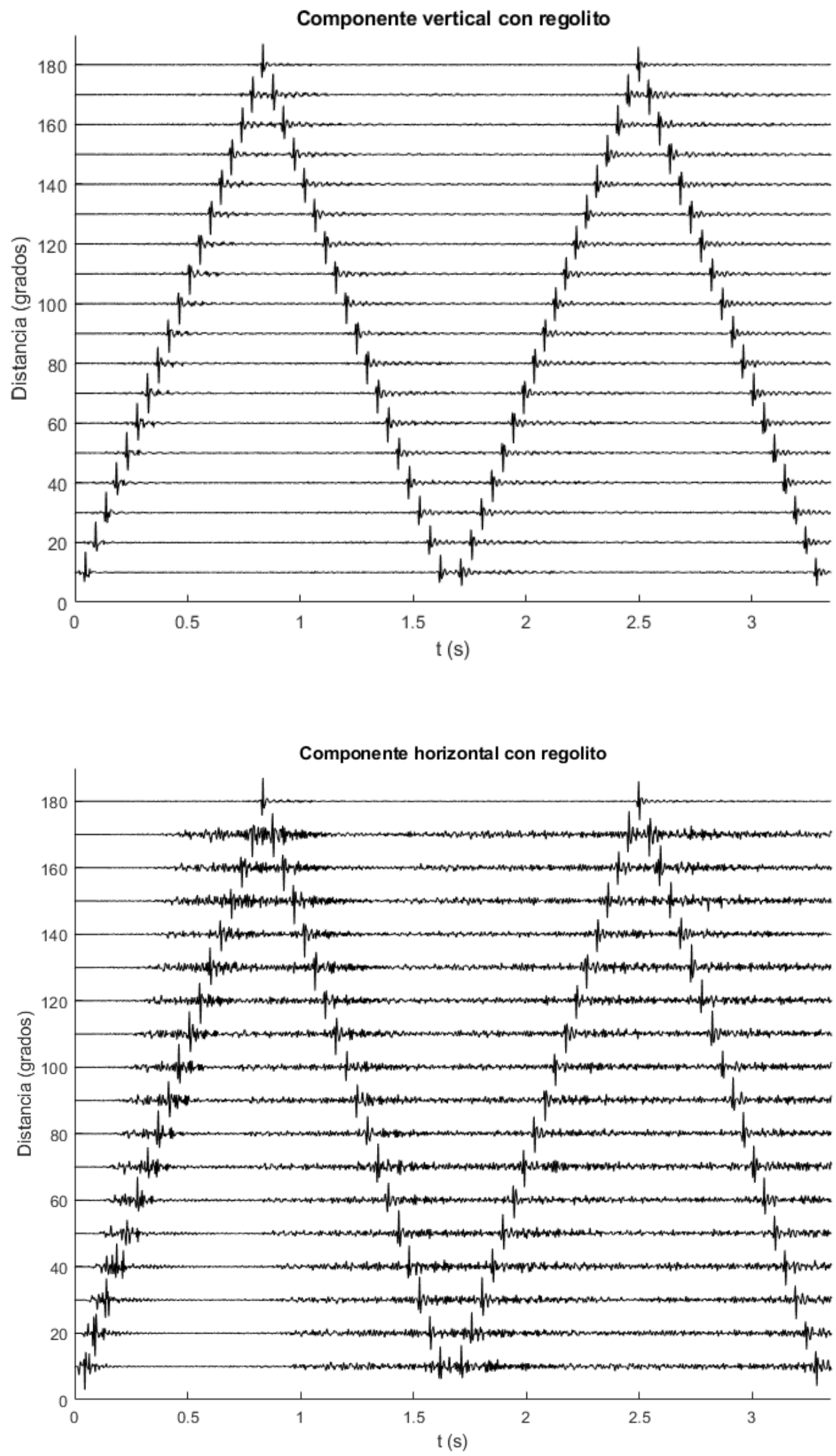

Figura 3.2. Componentes vertical y horizontal de los registros del modelo con regolito, normalizados a su respectiva máxima amplitud. Fuente de $100 \mathrm{~Hz}$. 
Los registros correspondientes a una fuente con la duración del periodo del mesh no son interesantes más allá de mencionar que las amplitudes máximas son evidentemente mayores al concentrar la energía en pulsos más estrechos y las fases sísmicas quedan mejor definidas. Tienen mejor resolución a nivel físico, pero no son realistas desde un punto de vista experimental.

\subsubsection{Snapshots e interpretación}

La secuencia completa de snapshots no puede plasmarse en la memoria y su presentación se ve limitada a instantes de interés. En particular, los instantes anteriores a la primera llegada de onda $\mathrm{P}$ en la antípoda muestran cómo van generándose las fases con las reflexiones y cómo se dispersan al tener distinta velocidad. Instantes cuando el campo de ondas ya se ha propagado por todo el cuerpo muestran cómo queda la distribución final de energía sísmica en el modelo.

$\mathrm{El}$ instante anterior a la primera llegada de onda $\mathrm{P}$ a la antípoda de la fuente es el que aparece en la Fig 3.3 para el modelo sin regolito y en la Fig 3.4 con el regolito. El modelo sin regolito es más fácil de interpretar al no tener la corteza fina, aunque el núcleo del modelo con regolito todavía puede interpretarse con relativa facilidad.

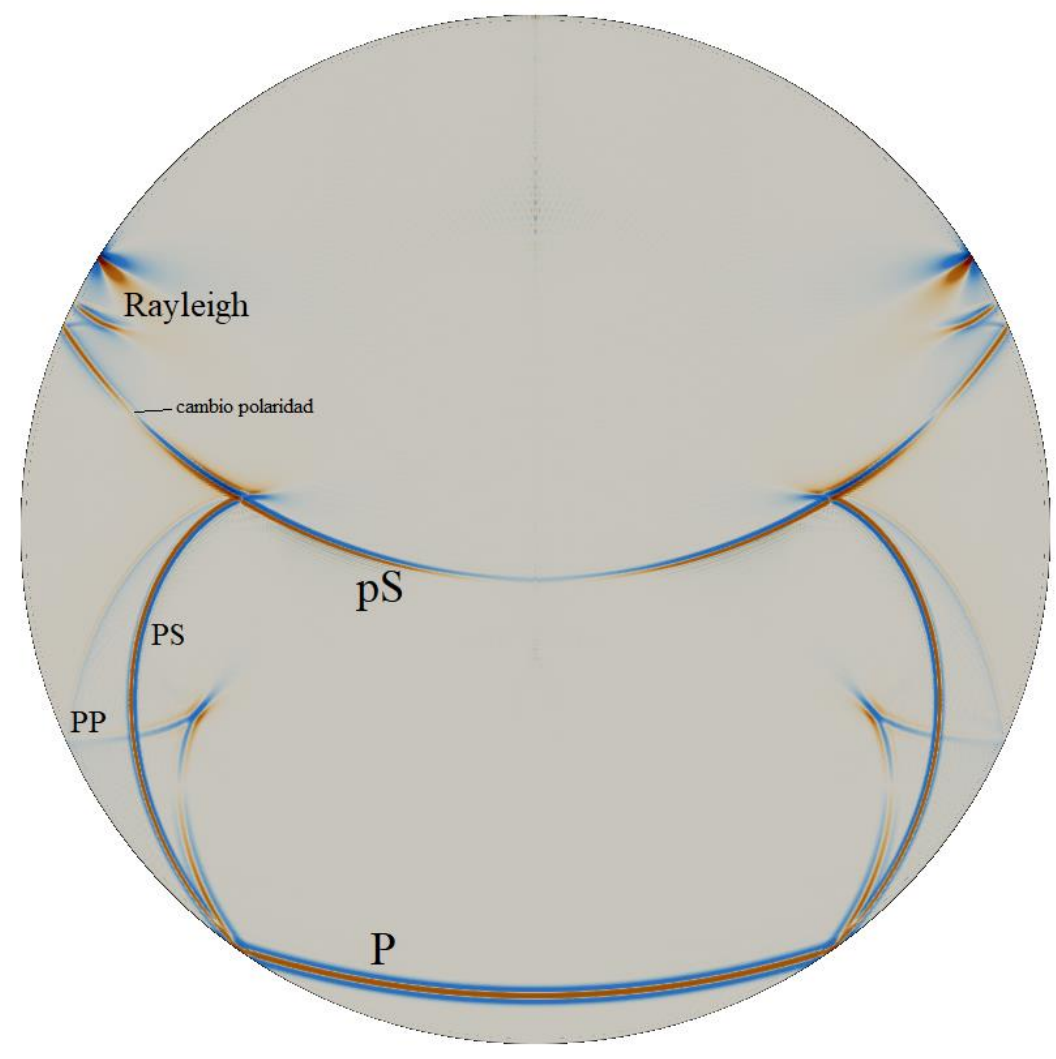

Figura 3.3. Modelo sin regolito $(t=0,085 \mathrm{~s})$. Campo de ondas en el instante anterior a la primera llegada $\mathrm{P}$ a la antípoda de la fuente. Se marcan algunas de las fases identificadas. El cambio de polaridad en la onda $\mathrm{S}$ se produce a $45^{\circ}$ de la fuente, donde la componente Norte de la $\mathrm{pS}$ cambia de polaridad. 


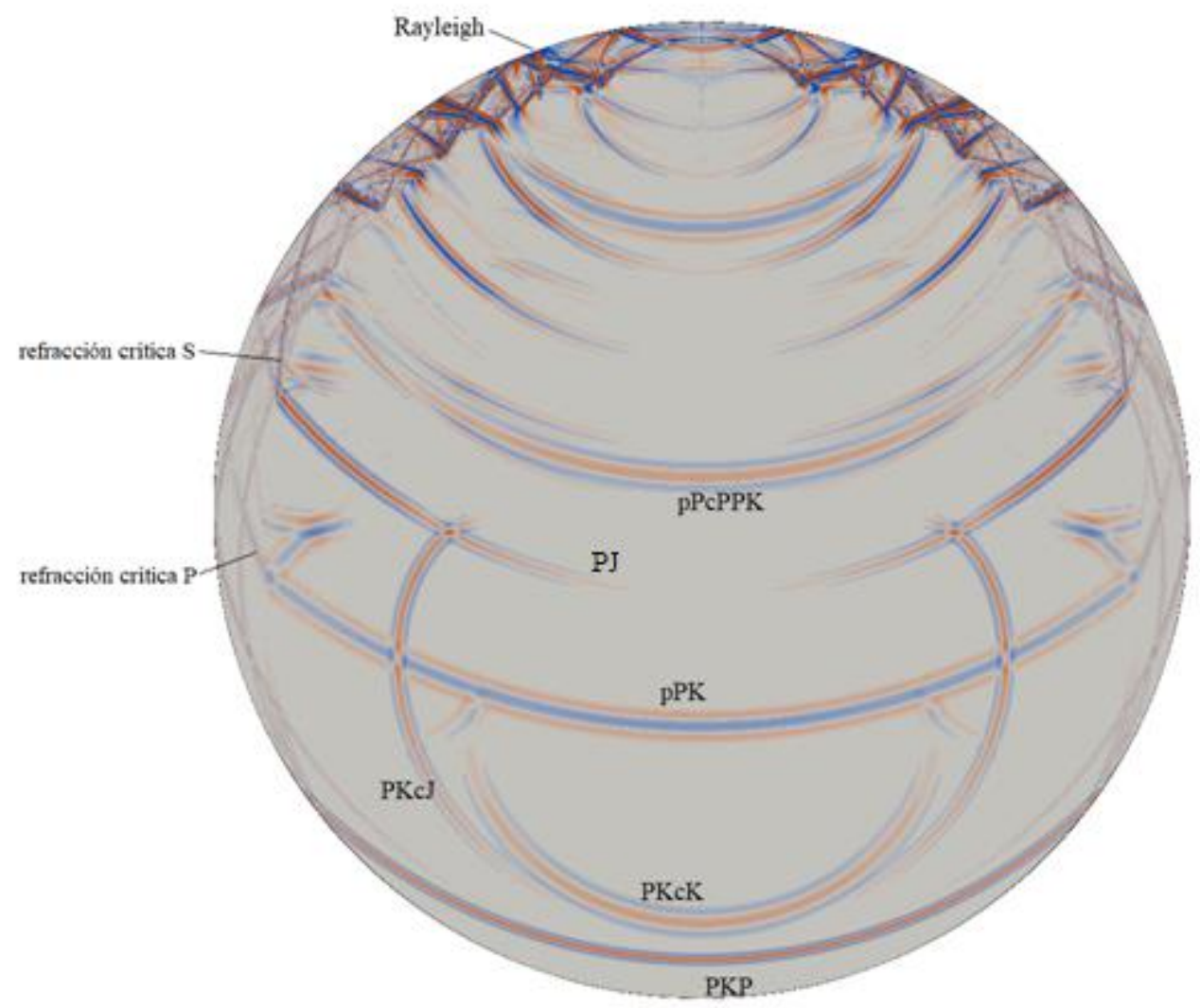

Figura 3.4. Modelo con regolito $(t=0,095 \mathrm{~s})$. Es completamente distinto dentro del regolito, donde se acumulan fases reflejadas y refractadas que han entrado previamente al núcleo. Dentro del núcleo todavía pueden diferenciarse bien fases, y destaca la presencia de múltiples frentes similares que se generan por los rebotes en la corteza.

La notación introducida distingue ondas $\mathrm{P}$ y $\mathrm{S}$ propagadas por el regolito de las que se propagan por el núcleo. La K es una onda $\mathrm{P}$ y la J una onda $\mathrm{S}$ (notación de onda $\mathrm{P}$ en el núcleo externo terrestre y onda $S$ en el núcleo interno) para que guarde cierto parecido con la notación usada en la Tierra. La "p" minúscula indica que es la onda P que sale de la fuente y rebota en la superficie que se encuentra justo encima, la "c" minúscula es una onda que rebota en la discontinuidad regolito-núcleo por cualquiera de los lados.

En el modelo homogéneo se puede apreciar una fase PP que se propaga hacia la superficie y se registra bien en las estaciones. La diferencia de velocidades es apreciable en las reflexiones y ondas directas. La onda $\mathrm{pS}$ no es directa, pero es lo más parecido a una onda directa S partiría de una fuente no isótropa. No obstante, las ondas S que se generan acaban teniendo amplitudes parecidas a las ondas $\mathrm{P}$, facilitando la visualización.

En el modelo con regolito se ven varias fases seguidas del mismo tipo cuya diferencia de caminos se debe al número de reflexiones que sufren en la corteza. En la antípoda de la fuente se registran fases $\mathrm{PcP}$ sucesivas que quedan atrapadas con pequeñas pérdidas por refracción. Una vez en el núcleo las ondas $\mathrm{P}$ adelantan a las $\mathrm{S}$. Se distinguen además por el patrón de amplitud opuesto, siendo las ondas $\mathrm{S}$ prácticamente inapreciables 
en las proximidades del eje. Se ven también refracciones críticas de las ondas que viajan por el núcleo y salen al regolito. Estas fases acaban llegando antes que la onda directa conforme aumenta la distancia entre la fuente y la estación, un fenómeno conocido que se utiliza en sísmica activa para caracterizar capas del terreno (sísmica de refracción). Se usan también las fases reflejadas (sísmica de reflexión).

Las técnicas utilizadas en problemas de sísmica activa pueden ser útiles en un experimento como el aquí contemplado, adaptándolos a la geometría del asteroide y teniendo en cuenta que se trabaja en un entorno cerrado. Que el modelo sea cerrado es importante porque, aunque en la práctica vaya a haber atenuación, se espera registrar fases con cierta recursividad.

$\mathrm{Al}$ ser isótropa, la fuente no genera ondas $\mathrm{S}$ y éstas solo pueden generarse a partir de reflexiones de la onda $\mathrm{P}$. La consecuencia de esto es la poca energía que se propaga en forma de onda S comparado a lo que se propagaría cuando la fuente las genera. En la práctica las explosiones no son perfectamente isótropas y la geometría del cartucho es relevante (Yang et al., 1999). Un impacto no es isótropo al tener un alto componente direccional que viene marcado por la dirección de la fuerza aplicada.

Instantes del campo de ondas ya bien propagado por el cuerpo se ven en la Fig 3.5 (sin regolito) y la Fig 3.6 (con regolito).

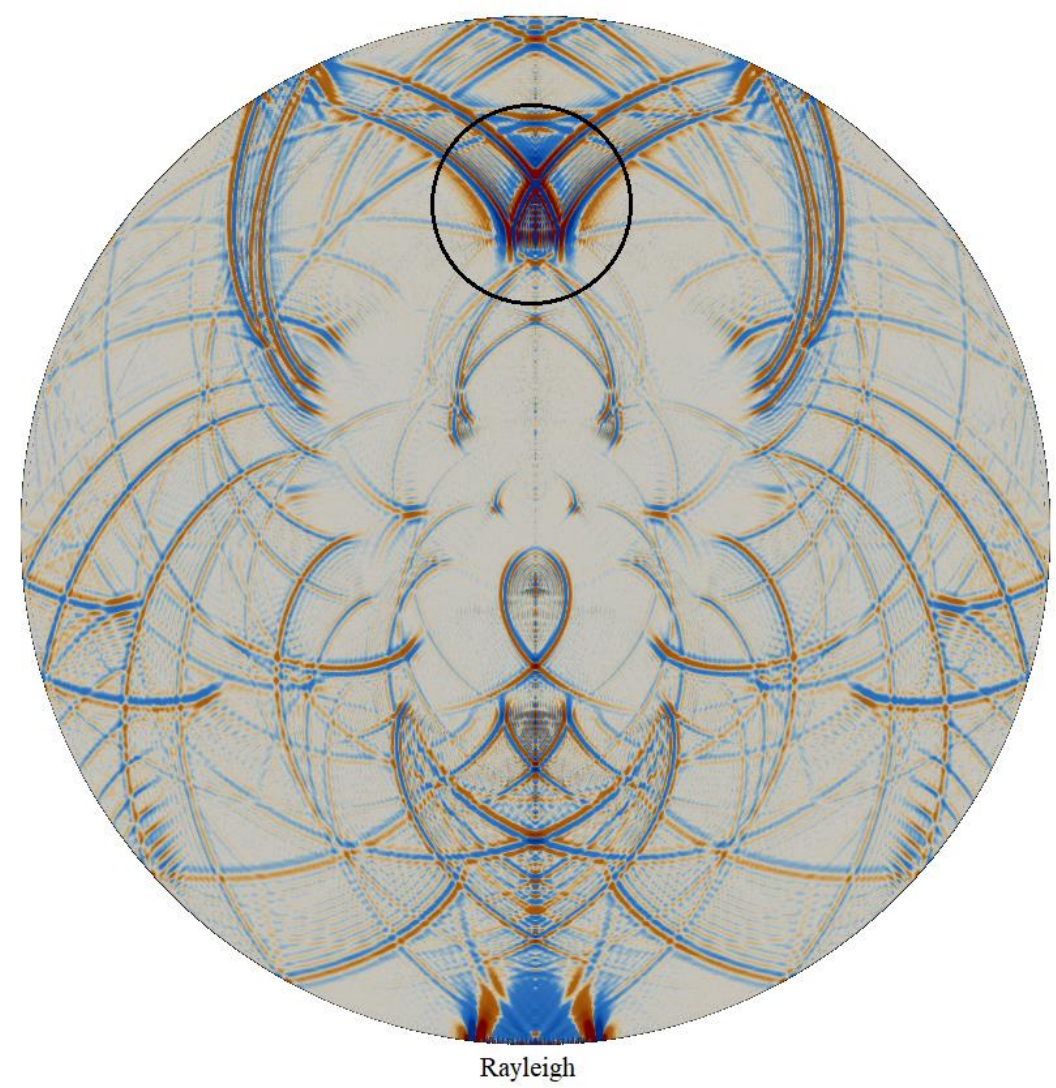

Figura 3.5. Modelo sin regolito $(t=0,765 \mathrm{~s})$. Se pueden ver las múltiples reflexiones en la superficie similar a lo que se ve al principio, pero ya muy desarrollado. En la antípoda de la fuente se distingue el frente de ondas superficiales a punto de interferir constructivamente ( $2^{\mathrm{a}}$ interferencia antipodal). Se destaca una acumulación de energía sobre el eje de simetría del problema (eje donde se sitúa la fuente). 


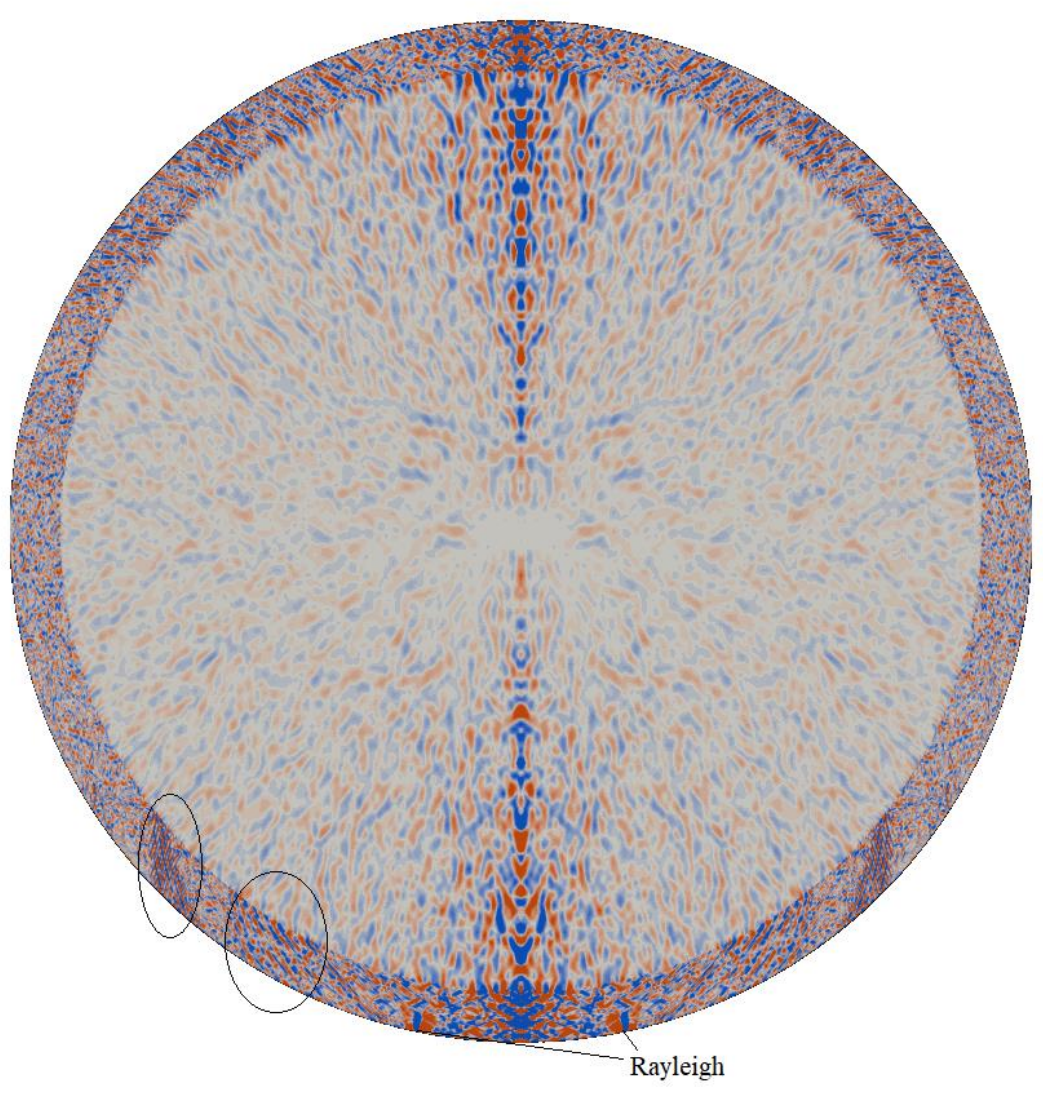

Figura 3.5. Modelo con regolito $(t=0,895 \mathrm{~s})$. La acumulación de energía sobre el eje donde se sitúa la fuente es clara. Apenas pueden distinguirse frentes definidos a excepción de las ondas Rayleigh que acaban de interferir constructivamente ( $1^{\mathrm{a}}$ interferencia antipodal). Se han marcado dos sucesiones de frentes de onda que todavía pueden distinguirse y están a punto de llegar a la antípoda. Aparecen en la coda del sismograma. Notar que el campo es mucho más difuso en este caso

Es aspecto es completamente distinto. El modelo con regolito confina gran parte de la energía en la corteza y apenas se distinguen frentes de onda mientras que en el modelo sin regolito todavía pueden seguirse sus trayectorias. En la práctica no se dispone de snapshots y por lo tanto la información se obtendría exclusivamente de los registros y prospección directa de la superficie. Tampoco existiría la simetría de estos modelos y las polarizaciones observadas en los registros darían información sobre la dirección con la que llegan las distintas fases al instrumento.

En un caso real sería de esperar que las ondas superficiales dieran vueltas por el asteroide siguiendo ciertas trayectorias hasta atenuarse. Los modos normales también se excitarían en función de la frecuencia del pulso inicial $(100 \mathrm{~Hz}$ en este caso) y se observarían bien antes de atenuarse. En la Tierra esto solo sucede con seísmos muy intensos (e.g. Sumatra 2004), pero en un cuerpo tan pequeño su aparición en los registros está garantizada para cualquier impacto a las velocidades habituales en la escala del Sistema Solar. 


\subsection{Exigencia instrumental}

Los sismogramas sintéticos aquí obtenidos son, a efectos prácticos, una señal continua. Cuando se quiere resolver el problema sísmico en un modelo teórico conviene utilizar un mesh de generosa resolución para garantizar la convergencia. Hacer esto implica utilizar un salto temporal muy pequeño en comparación al máximo que, teóricamente, podría utilizarse. El salto temporal equivale a la frecuencia de muestreo con la que se "registra" el sismograma, que en los casos aquí presentados equivalen a $86.207 \mathrm{~Hz}$ con regolito y $62.893 \mathrm{~Hz}$ sin regolito. Estas frecuencias están muy por encima de lo que un instrumento sería capaz de recuperar.

\subsubsection{Espectro de los sismogramas}

Un primer análisis que se puede hacer de los sismogramas sintéticos es el espectro para comprobar que la convolución los ha suavizado correctamente. Se espera un espectro centrado en torno a los $100 \mathrm{~Hz}$ con los que la fuente excita el medio. Picos adicionales serán debidos a particularidades del modelo, como pueden ser modos fundamentales que el pulso inicial es capaz de excitar.

Se utiliza el registro de la estación en la antípoda (distancia de $180^{\circ}$ ) al estar menos afectado por el ruido numérico en ambos modelos. La Fig 3.7 corresponde al modelo sin regolito y la Fig 3.8 al modelo con regolito.

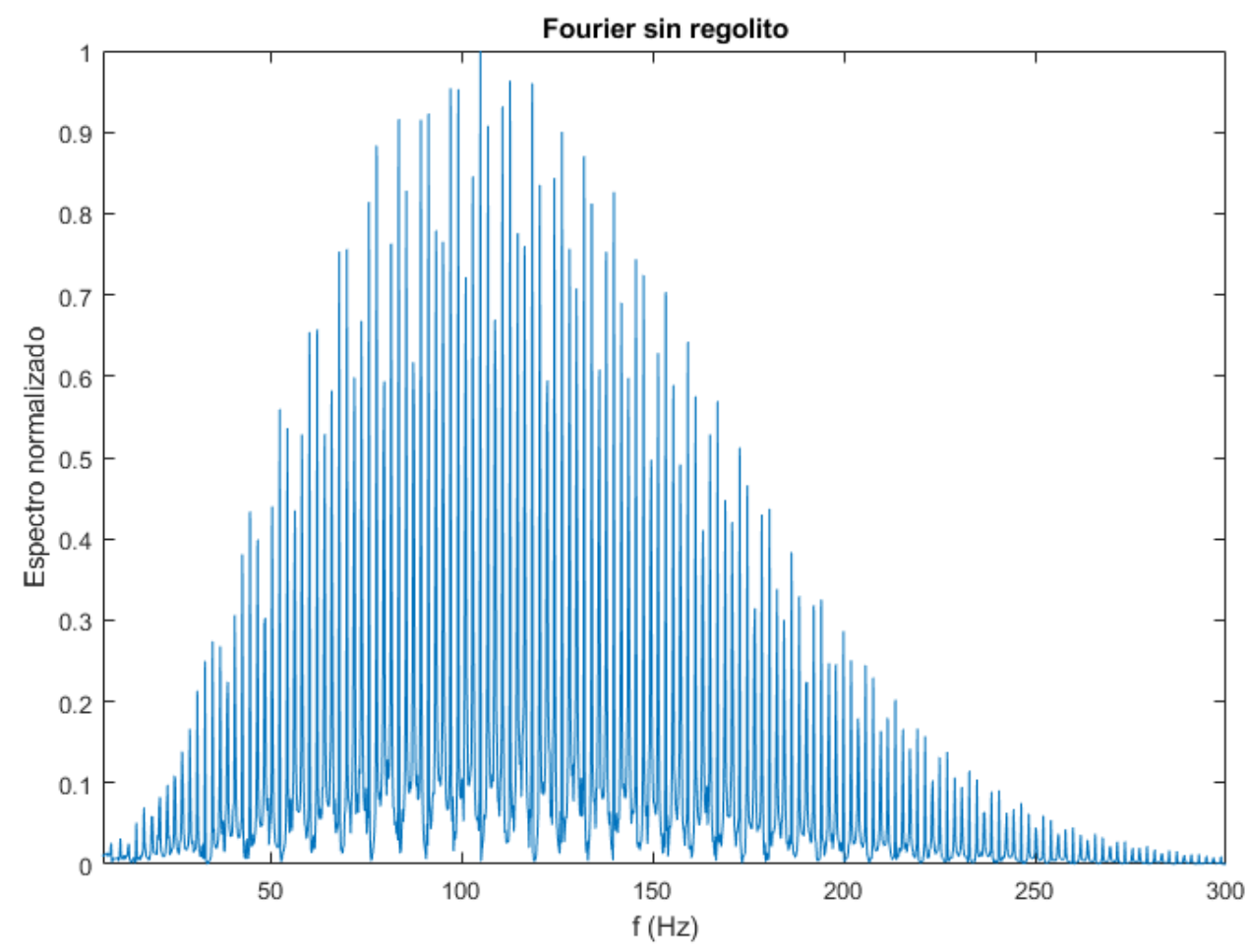

Figura 3.7. Espectro correspondiente a una fuente de $100 \mathrm{~Hz}$ en el modelo sin regolito. El resultado es el esperado. 


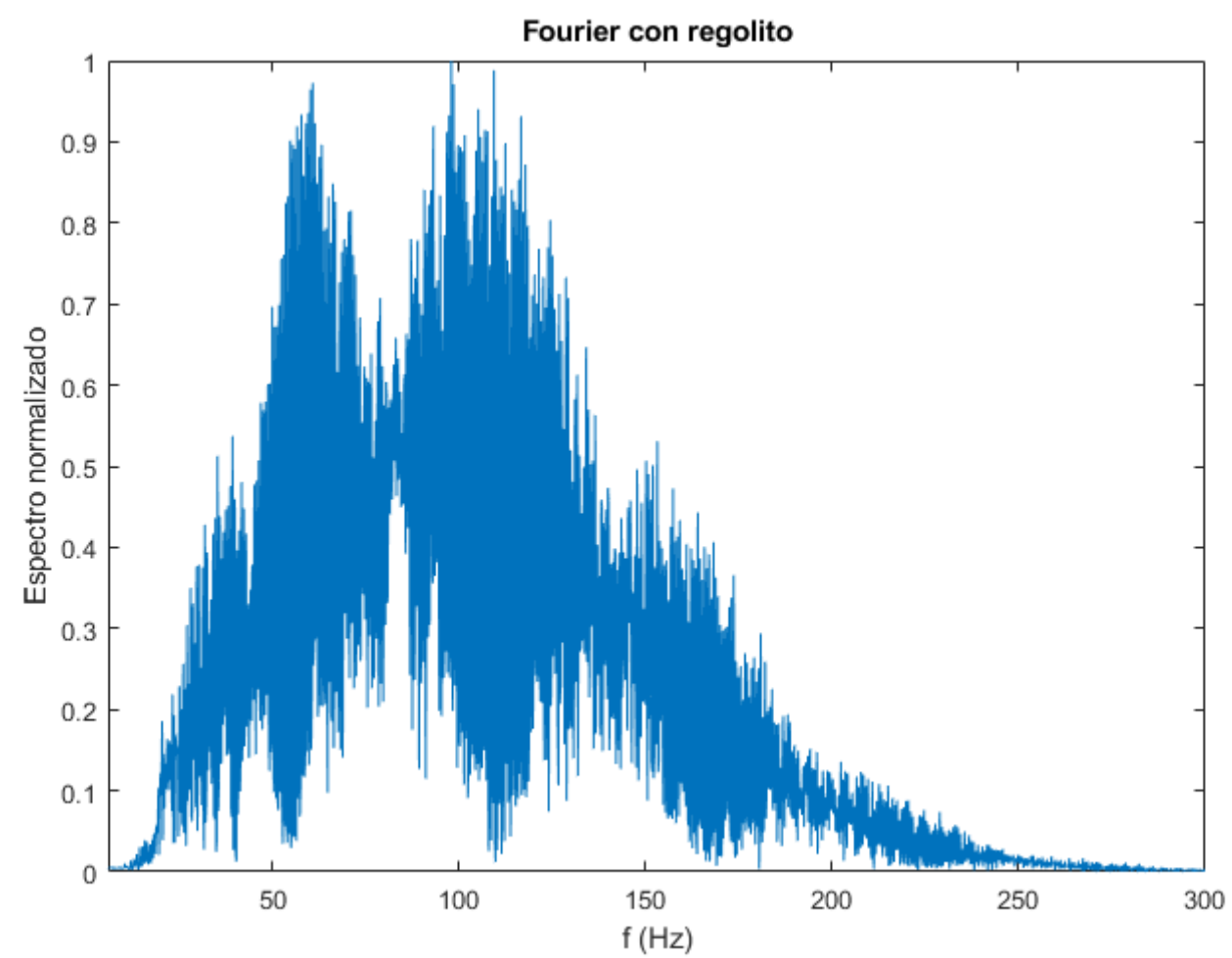

Figura 3.8. Espectro correspondiente a una fuente de $100 \mathrm{~Hz}$ en el modelo con regolito. Aparece un pico adicional cerca de $60 \mathrm{~Hz}$ que corresponden a resonancias en la capa de regolito.

Del primer espectro puede deducirse que la frecuencia de excitación es $100 \mathrm{~Hz}$, mientras que en el segundo la distribución del modelo hace que aparezca un pico cerca de los $60 \mathrm{~Hz}$. Esto corresponde a resonancias en la capa de regolito. Las ondas superficiales también son más energéticas en este modelo al quedar la energía atrapada en la corteza y eso influye en el espectro. Añadir topografía y una estructura interna más compleja se reflejaría también en el espectro, de ahí su valor, especialmente cuando se utiliza una fuente conocida y ensayada previamente.

\subsubsection{Frecuencia de muestreo}

El propio espectro ya restringe los valores mínimos de frecuencia de muestreo que deben utilizarse para poder registrar señales útiles en un experimento que use una fuente de esta duración. El teorema de Nyquist da una frecuencia mínima, el doble de la original, para recuperar una señal. En este caso podrían ser unos $500 \mathrm{~Hz}$, pero en un experimento sísmico interesa también poder recuperar la forma de las ondas, por lo que también puede ser conveniente muestrear en exceso.

Una frecuencia de muestreo típica en experimentos de sísmica activa son $1000 \mathrm{~Hz}$, y se prueba también con $500 \mathrm{~Hz}$ teniendo en cuenta las posibles limitaciones a la hora de enviar datos a la Tierra (se mandaría la mitad de información). Los muestreos en dos segmentos arbitrarios de cada sismograma aparecen en la Fig 3.9 (sin regolito) y la Fig 3.10 (con regolito). 

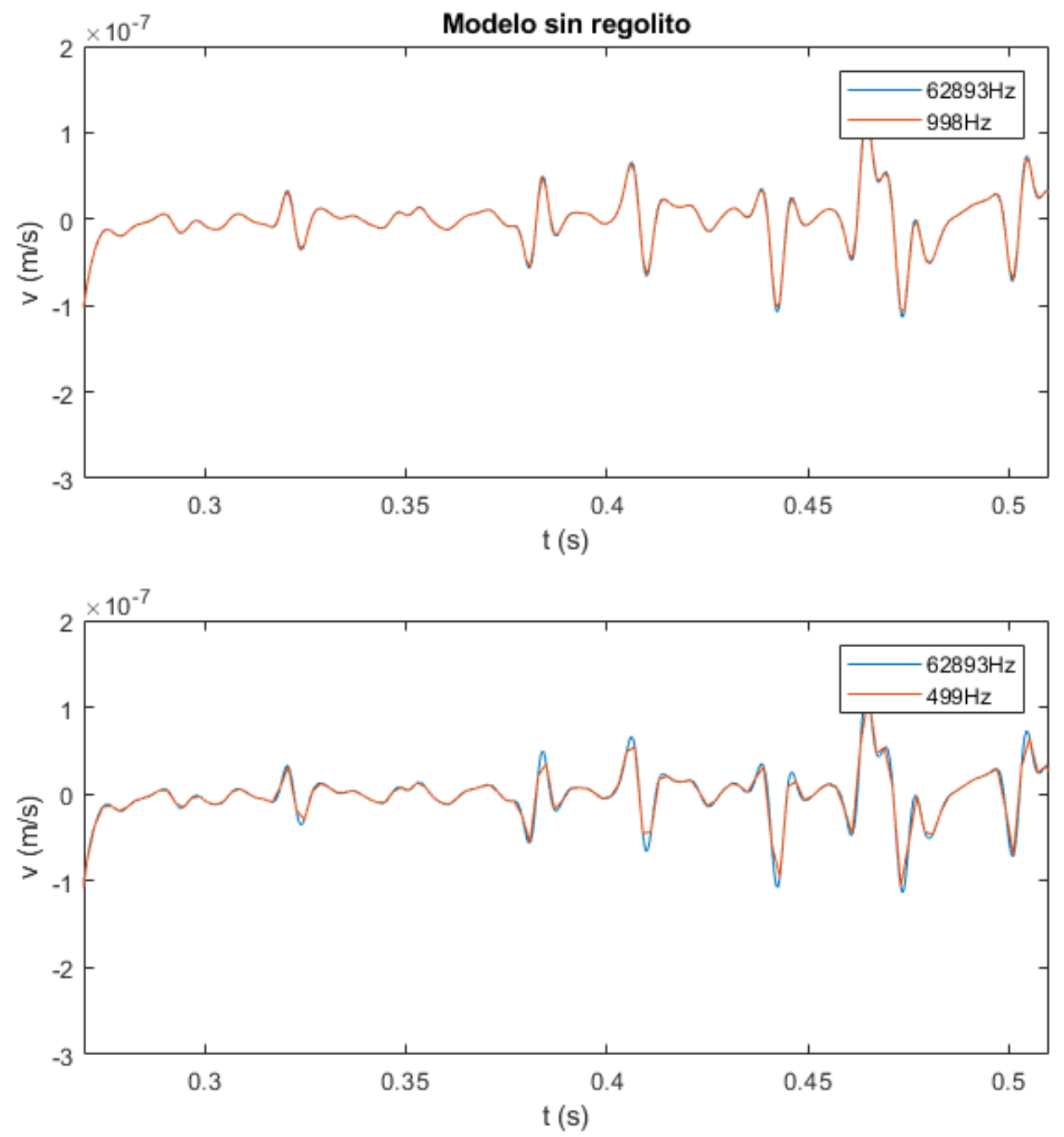

Figura 3.9. Modelo sin regolito. Señal recuperada a muestrear con $1000 \mathrm{~Hz}$ y $500 \mathrm{~Hz}$ el mismo segmento del sismograma original. Las frecuencias son divisores de la original para evitar distorsionar el sismograma original.

Muestrear a $500 \mathrm{~Hz}$ permite recuperar razonablemente el sismograma original en ambos casos, aunque se pierde suavidad en algunos picos. Las fases más intensas pueden quedar peor registradas y no obtener información precisa de la amplitud. No obstante, sigue siendo una opción válida si no hay alternativa. Con las tres componentes se registran 1500 valores por segundo. Se debe tener en cuenta al elegir un formato de almacenamiento.

El muestreo a $1000 \mathrm{~Hz}$ recupera bien el sismograma y la forma de onda, lo que lo hace ideal en el caso de poder almacenar los 3000 valores por segundo. Evidentemente, frecuencias de muestreo más altas devolverían un mejor registro a cambio del coste incrementado.

El segmento utilizado para el modelo con regolito corresponde a la coda que viene tras la primera llegada de onda Rayleigh, y corresponde a los frentes señalados con círculos en la Fig 3.5. La oscilación de largo periodo que puede apreciarse claramente corresponde a un pico centrado en $21 \mathrm{~Hz}$ que domina el espectro del segmento en cuestión. 

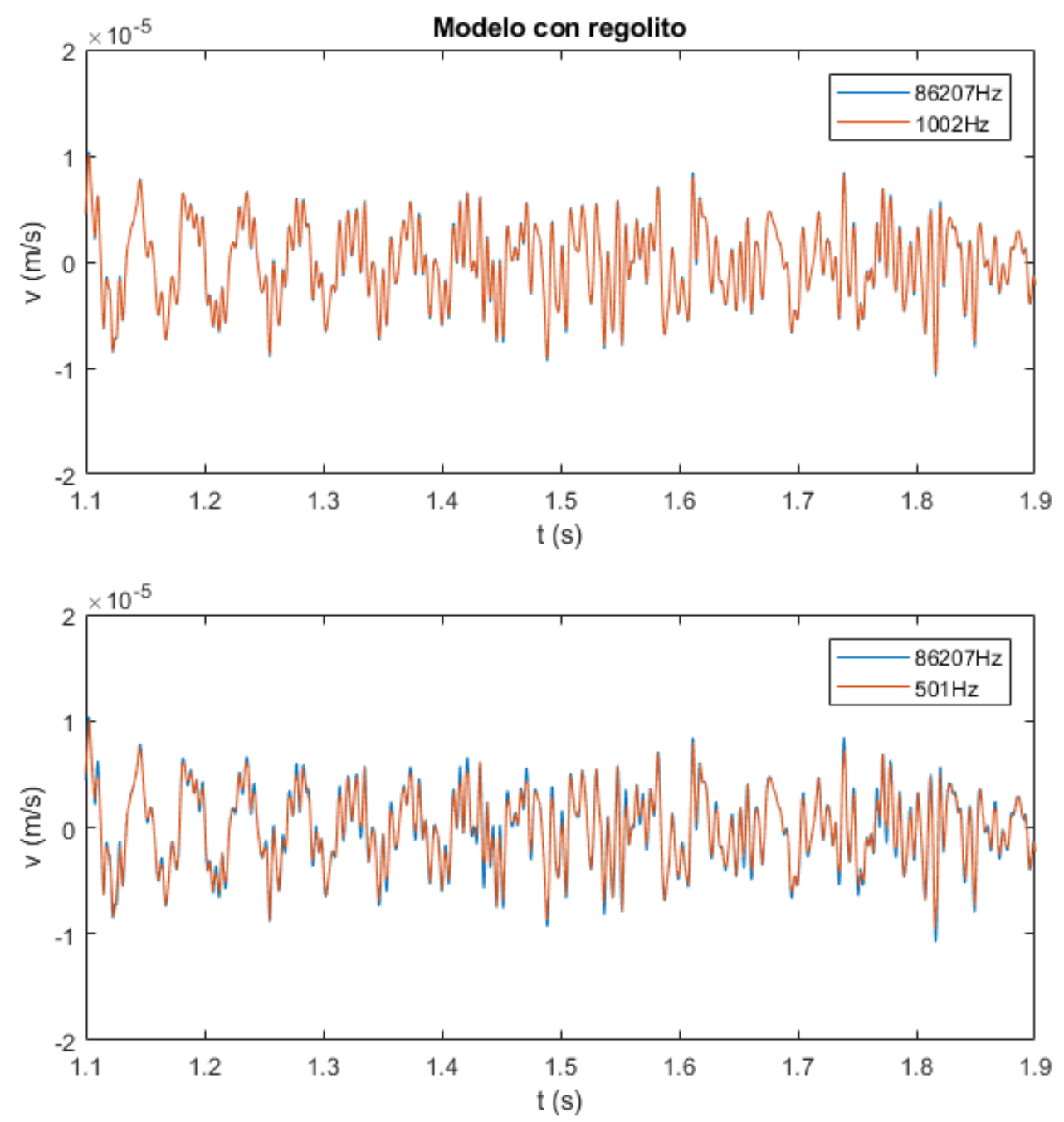

Figura 3.10. Modelo con regolito. Señal recuperada a muestrear con $1000 \mathrm{~Hz}$ y $500 \mathrm{~Hz}$ el mismo segmento del sismograma original. Las frecuencias son divisores de la original para evitar distorsionar el sismograma original.

\subsection{Análisis de los sismogramas}

En este apartado se analizan algunos aspectos de los sismogramas que pueden ser útiles con cualquier conjunto de registros experimentales.

\subsubsection{Comparación de amplitudes}

En estos modelos, la amplitud y la cantidad de fases registradas depende del regolito. En la práctica el problema sería más complejo, pero la idea fundamental se mantendría: una capa de regolito sobre un material más consolidado retendrá en su corteza una energía que un modelo enteramente consolidado distribuiría por su interior. En la Fig 3.11 aparecen los sismogramas verticales de ambos modelos correspondientes a la estación situada a $90^{\circ}$ de la fuente (estación 9). 


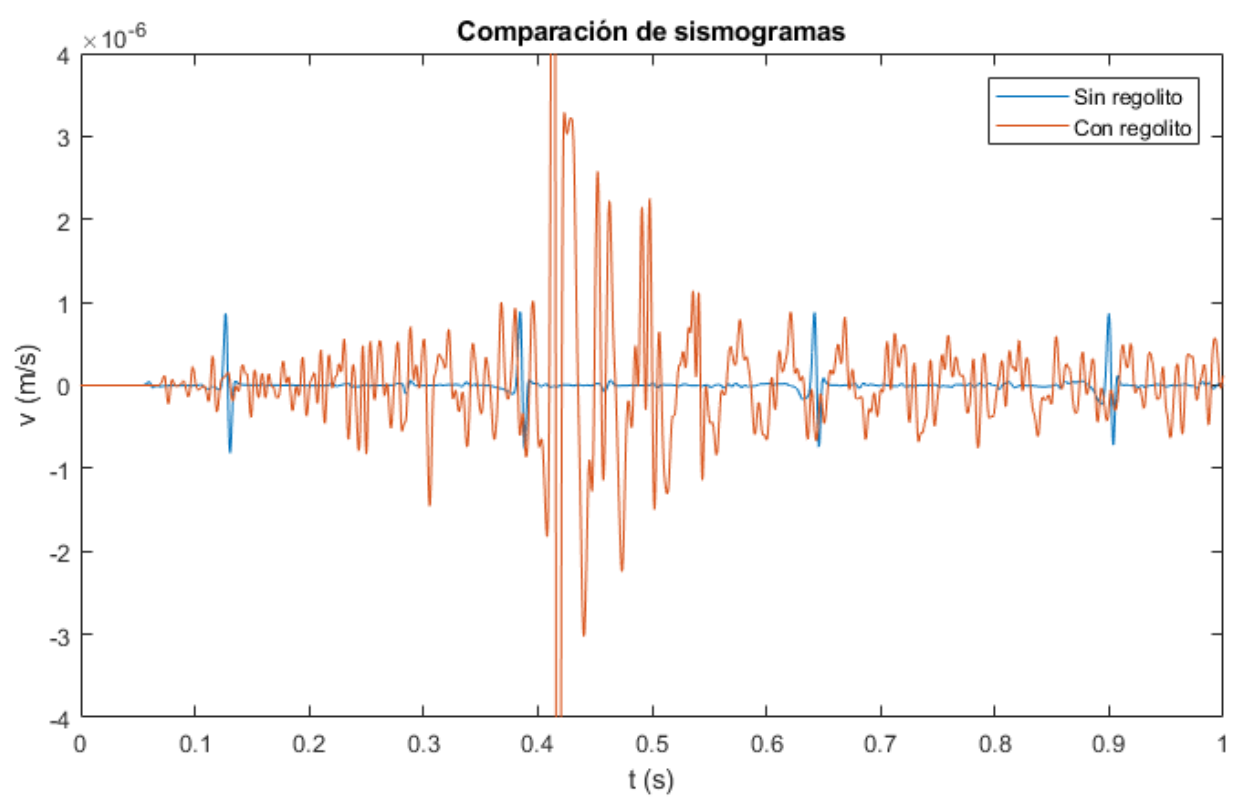

Figura 3.11. Comparación de sismogramas a una distancia epicentral de $90^{\circ}$. El modelo con regolito acumula más energía en la superficie en forma de ondas guiadas por el regolito. Componente vertical.

La onda Rayleigh es mucho más rápida en el modelo sin regolito debido a la diferencia de velocidades en la superficie, pero la característica a destacar aquí es la diferencia de amplitudes. Cuando la velocidad en la superficie es menor que en el interior, la energía puede quedar atrapada y manifestarse en forma de más fases reflejadas y refractadas críticamente, así como amplitudes mayores para una misma fuente. La cantidad de fases adicionales también es evidente en la propia figura.

Pondrían generarse también ondas Love en un modelo con corteza de regolito de baja velocidad, pero los casos aquí contemplados no se generan. En cualquier caso, son ondas con polarización horizontal y no se registran en la componente vertical.

La relación de amplitudes Rayleigh es $R_{r} / R_{m}=20,25$ para la velocidad del suelo. La relación es todavía mayor para el desplazamiento y en general se puede tener una idea de la cantidad que es capaz de confinar el regolito.

\subsubsection{Aceleración y velocidad del suelo}

Una de las cuestiones a la hora de evaluar la sismicidad en estos cuerpos es comparar la aceleración del suelo con la aceleración de la gravedad y así comprobar el posible impacto geomorfológico del campo de ondas generado por un impacto. Más allá de la fabricación y desplazamiento de regolito que se produciría en la craterización, se evalúa teóricamente el posible desplazamiento vertical de regolito cuando la aceleración del suelo compensa y supera la microgravedad del cuerpo que mantiene el regolito reposando sobre la superficie (Fig 3.12). 

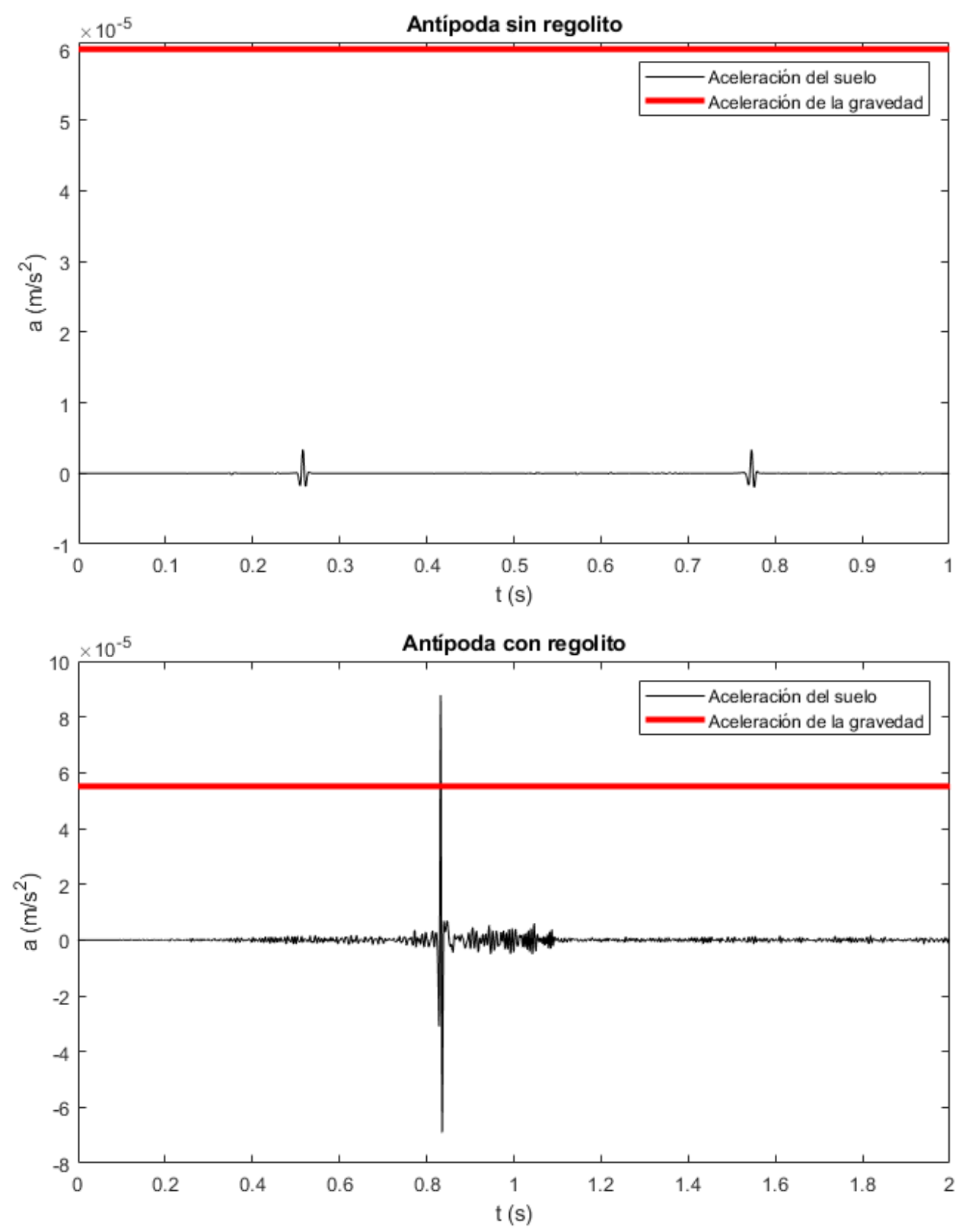

Figura 3.12. Aceleración del suelo en la componente vertical de la antípoda de ambos modelos comparada con la aceleración de la gravedad correspondiente a cada modelo. El valor señalado para la gravedad es el que debe superarse para que la aceleración resultante sobre la superficie cambie de sentido y debe libre el regolito.

En los sismogramas obtenidos, solo la interferencia constructiva en la antípoda del modelo con regolito es capaz de superar la aceleración de la gravedad. Esto es un resultado particular de este modelo, la fuente isótropa y la simetría resultante al combinar ambos, pero hace evidente la posibilidad de conseguir aceleraciones suficientes en modelos más complejos si la fuente es lo suficientemente energética. Aquí se ha reducido la magnitud para asegurar que no se están dando valores capaces de destruir el objetivo. Con la fuente adecuada se puede superar la aceleración de la gravedad sin superar la velocidad de escape (Garcia et al., 2015; Murdoch et al., 2017), lo que garantiza que el material vuelve a descender a la superficie. El movimiento aleatorio de las partículas bajo estas condiciones puede modelarse como un fluido (Quillen et al., 2019). 
En los casos aquí presentados, las velocidades de escape son $\mathrm{v}_{\mathrm{em}}=0,109 \mathrm{~m} / \mathrm{s} \sin$ regolito $\mathrm{y} \mathrm{v}_{\mathrm{er}}=0,105 \mathrm{~m} / \mathrm{s}$ con regolito. Las velocidades verticales registradas para la fase Rayleigh son del orden de $10^{-5} \mathrm{~m} / \mathrm{s}$ y las aceleraciones del orden de $10^{-6} \mathrm{~m} / \mathrm{s}^{2}$. Tan solo con lograr un orden más de magnitud se darían las condiciones para levantar polvo de la superficie sin que llegue a escapar, ya que las aceleraciones de la gravedad son tan solo un orden de magnitud superiores. Velocidad y aceleración cambian proporcionalmente.

\subsubsection{Fase Rayleigh}

Las ondas superficiales se propagan por el regolito con una velocidad que depende de sus propiedades. Seguir su trayectoria y velocidad a lo largo de los registros aporta información de la superficie del asteroide. La trayectoria en estos modelos es trivial, pero la velocidad se puede calcular análogamente a cómo se haría con una serie de registros experimentales donde se ha identificado una fase Rayleigh y sus recurrencias (R1, R2, $\mathrm{R} 3$, etc.), que son las vueltas completas que realiza sobre la superficie.

Los tiempos de llegada para R1 (primera llegada) en ambos modelos se recogen en la Tabla 3.1 para luego ajustarlos a la recta correspondiente. La pendiente de la recta es la velocidad, en grados de arco por segundo, de la onda Rayleigh. Se puede convertir a m/s considerando la longitud del arco. Ajuste en la Fig 3.13.

Tabla 3.1. Tiempos de llegada de la fase Rayleigh R1 para una serie de estaciones a una cierta distancia de la fuente sin llegar a la antípoda.

\begin{tabular}{c|cc}
\hline Distancia epicentral (grados) & Con regolito & Sin regolito \\
\hline $\mathbf{4 0}$ & $0,177 \mathrm{~s}$ & $0,051 \mathrm{~s}$ \\
$\mathbf{5 0}$ & $0,223 \mathrm{~s}$ & $0,065 \mathrm{~s}$ \\
$\mathbf{6 0}$ & $0,270 \mathrm{~s}$ & $0,079 \mathrm{~s}$ \\
$\mathbf{7 0}$ & $0,313 \mathrm{~s}$ & $0,093 \mathrm{~s}$ \\
$\mathbf{8 0}$ & $0,361 \mathrm{~s}$ & $0,108 \mathrm{~s}$ \\
$\mathbf{9 0}$ & $0,409 \mathrm{~s}$ & $0,122 \mathrm{~s}$ \\
$\mathbf{1 0 0}$ & $0,453 \mathrm{~s}$ & $0,136 \mathrm{~s}$ \\
$\mathbf{1 1 0}$ & $0,501 \mathrm{~s}$ & $0,150 \mathrm{~s}$ \\
$\mathbf{1 2 0}$ & $0,545 \mathrm{~s}$ & $0,164 \mathrm{~s}$ \\
$\mathbf{1 3 0}$ & $0,591 \mathrm{~s}$ & $0,177 \mathrm{~s}$ \\
$\mathbf{1 4 0}$ & $0,636 \mathrm{~s}$ & $0,193 \mathrm{~s}$ \\
$\mathbf{1 5 0}$ & $0,683 \mathrm{~s}$ & $0,208 \mathrm{~s}$ \\
$\mathbf{1 6 0}$ & $0,730 \mathrm{~s}$ & $0,222 \mathrm{~s}$ \\
$\mathbf{1 7 0}$ & $0,774 \mathrm{~s}$ & $0,236 \mathrm{~s}$ \\
\hline
\end{tabular}




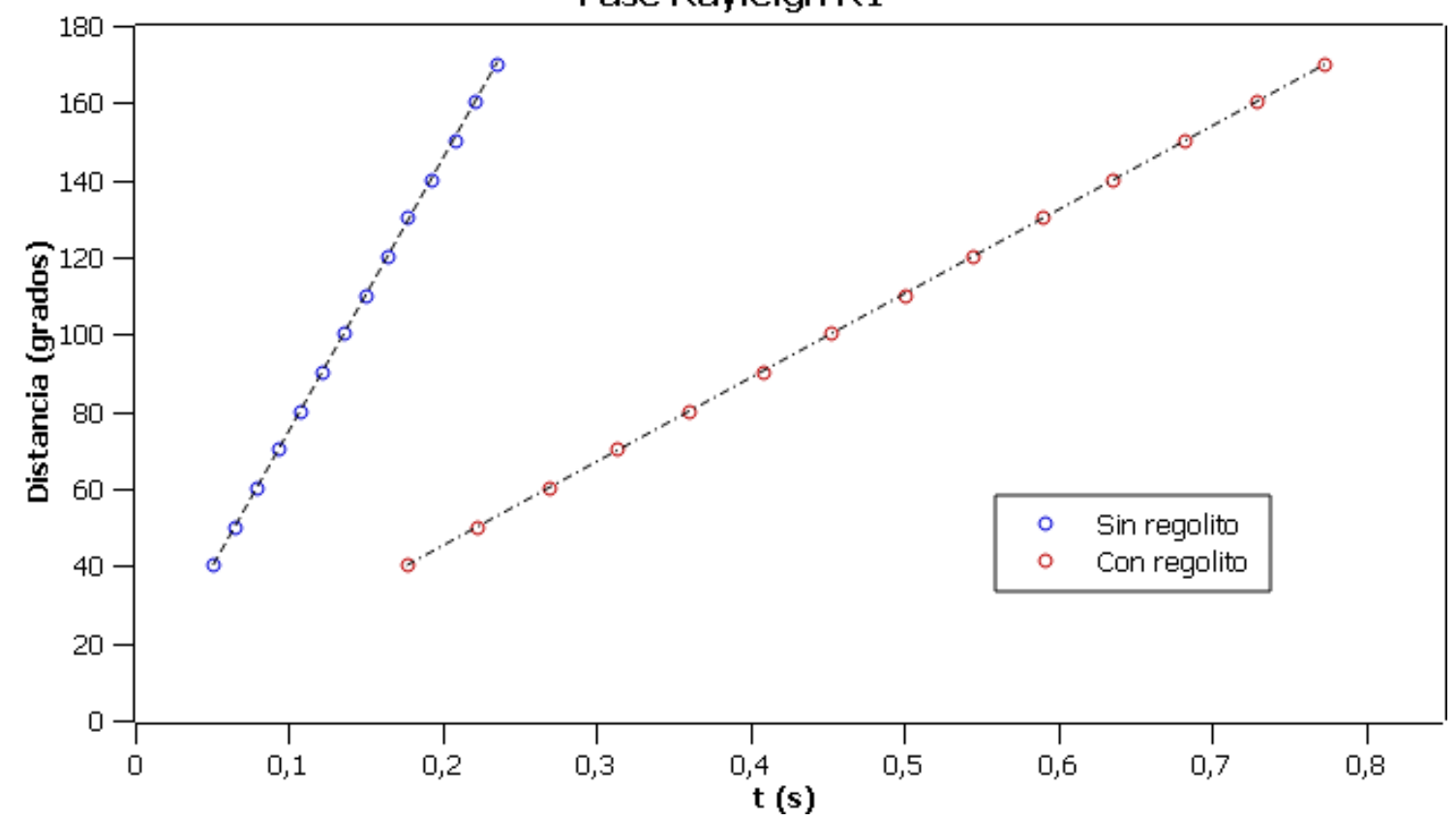

Figura 3.13. Rectas de ajuste para la primera fase Rayleigh registrada en las estaciones. Sin regolito la onda se desplaza a 702 grados/s y con regolito a 217 grados/s.

Estas rectas corresponden a velocidades de $\mathrm{V}_{\mathrm{Rm}}=1225 \mathrm{~m} / \mathrm{s}$ en el modelo sin regolito y $\mathrm{V}_{\mathrm{Rr}}=379 \mathrm{~m} / \mathrm{s}$ en el modelo con regolito. Se ha considerado la longitud del arco para obtener velocidades en $\mathrm{m} / \mathrm{s}$. Aquí es conveniente referirse a las ecuaciones utilizadas anteriormente para asignar velocidades en ambos modelos (Quillen et al., 2019). Hay una última relación aproximada para la velocidad de las ondas Rayleigh.

$$
\mathrm{V}_{\mathrm{Ra}} \approx \mathrm{V}_{\mathrm{s}} \frac{0,862+1,14 v}{1+v}
$$

Al trabajar con la hipótesis del sólido de Poisson la relación queda en $\mathrm{V}_{\mathrm{Ra}}=$ $0,92 \cdot \mathrm{V}_{\mathrm{s}} \mathrm{y}$ se puede comparar con las velocidades teóricas que da el modelo. Utilizando las velocidades de onda $S$ del modelo ( $1326 \mathrm{~m} / \mathrm{s}$ sin regolito, $400 \mathrm{~m} / \mathrm{s}$ con regolito) se obtienen velocidades de onda Rayleigh $\mathrm{V}_{\mathrm{Ra}}=1220 \mathrm{~m} / \mathrm{s}$ para el modelo sin regolito y $\mathrm{V}_{\mathrm{Ra}}$ $=368 \mathrm{~m} / \mathrm{s}$ para el modelo sin regolito. El resultado está de acuerdo con lo que se observa en las simulaciones y la aproximación es buena. En este caso se ha comprobado que se trata de una fase Rayleigh, algo que ya se deduce a partir de las amplitudes y los snapshots.

Algo a tener en cuenta es que el modelo sin el regolito es un sólido de Poisson en su totalidad, mientras que la corteza de regolito tiene una velocidad de onda $\mathrm{P}$ por encima de la que le correspondería si fuera un sólido de Poisson. El coeficiente de Poisson puede calcularse a partir de las velocidades de onda $\mathrm{P}$ y $\mathrm{S}$ despejándolo de la relación correspondiente.

$$
v=\frac{1}{2} \frac{\left(\mathrm{V}_{\mathrm{p}}^{2}-2 \mathrm{~V}_{\mathrm{s}}^{2}\right)}{\left(\mathrm{V}_{\mathrm{p}}^{2}-\mathrm{V}_{\mathrm{s}}^{2}\right)}
$$

Para la corteza su valor es $v=0,38$ y la velocidad Rayleigh resultante es $V_{\mathrm{Ra}}=$ $375 \mathrm{~m} / \mathrm{s}$ que ajusta mejor el valor previamente determinado. Las ondas superficiales serán 
fundamentales para determinar las propiedades del regolito en un experimento real, dado que viajan exclusivamente por la superficie y su comportamiento dependerá de cómo sea el material del regolito y su profundidad.

\subsubsection{Primeras llegadas y justificación de la fuente}

Normalizando los sismogramas verticales respecto a un valor común se pueden comparar los registros antes de la primera llegada Rayleigh (R1) teniendo en cuenta las amplitudes. En la Fig 3.14 se destacan algunas de las fases presentes en los sismogramas del modelo sin regolito. La fase $\mathrm{S}$ es una onda que viaja por la superficie junto con la $\mathrm{pS}$ que viaja hacia la antípoda. La fuente explosiva ha resultado ser una buena alternativa pese a ser isótropa y no radiar ondas $\mathrm{S}$. Al estar tan próxima a la superficie se genera en la primera reflexión una onda $\mathrm{pS}$ que actúa como una onda pseudodirecta con menor amplitud de la que tendrían las ondas $\mathrm{S}$ directas de una fuente capaz de emitirlas.

En la Fig 3.15 aparecen los sismogramas del modelo con regolito, sin destacar fases al haber muchas reflexiones y refracciones llenando el campo de ondas. Destacan las amplitudes en la antípoda, comparativamente mayores porque la incidencia es prácticamente vertical (ver Fig 3.2, amplitud horizontal mayor en el resto de estaciones).

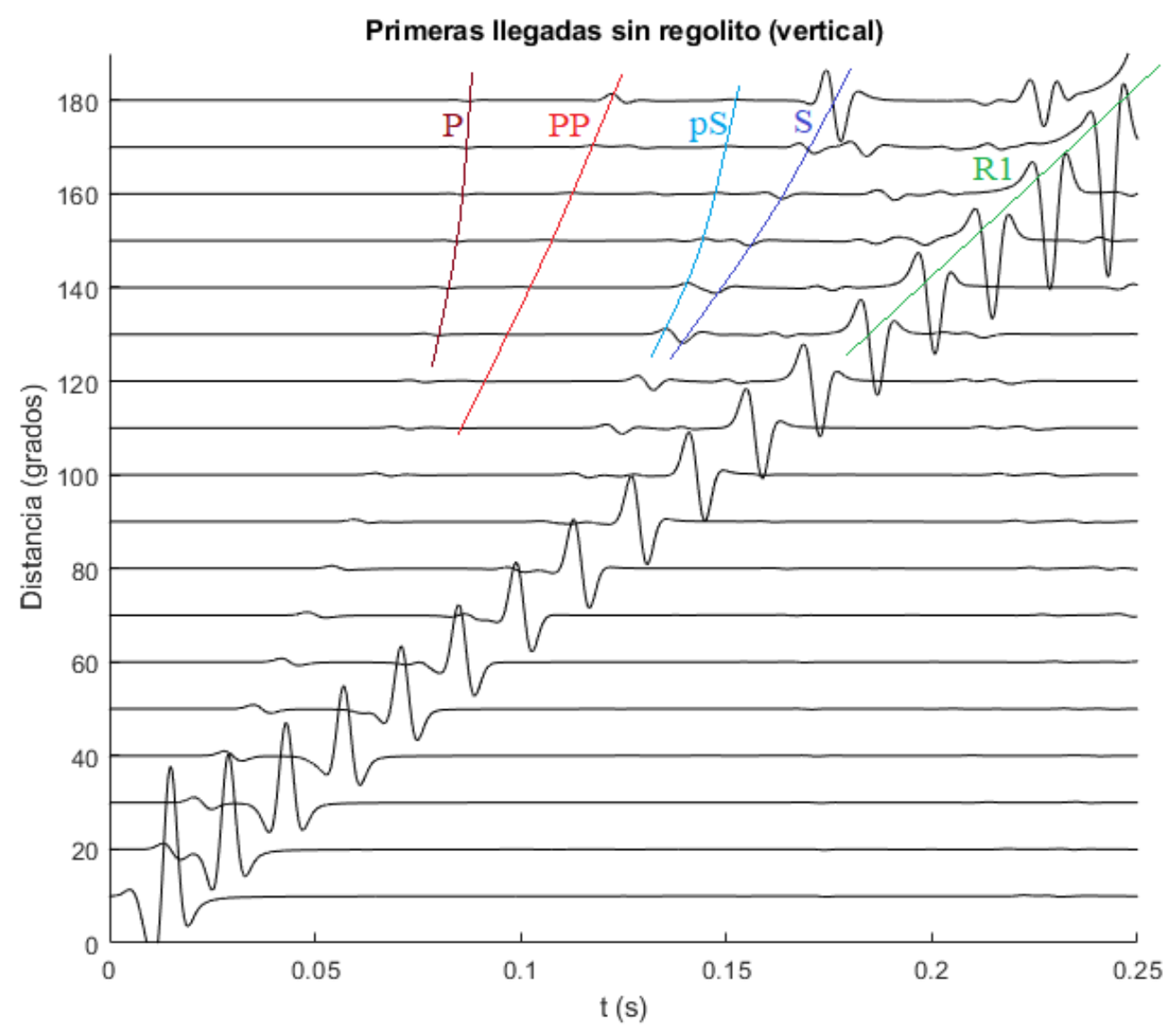

Figura 3.14. Primeras llegadas en el modelo sin regolito. Aparecen marcadas algunas de las fases que pueden verse bien. La S corresponde a una onda intensa que llega poco después de la pS directa. 


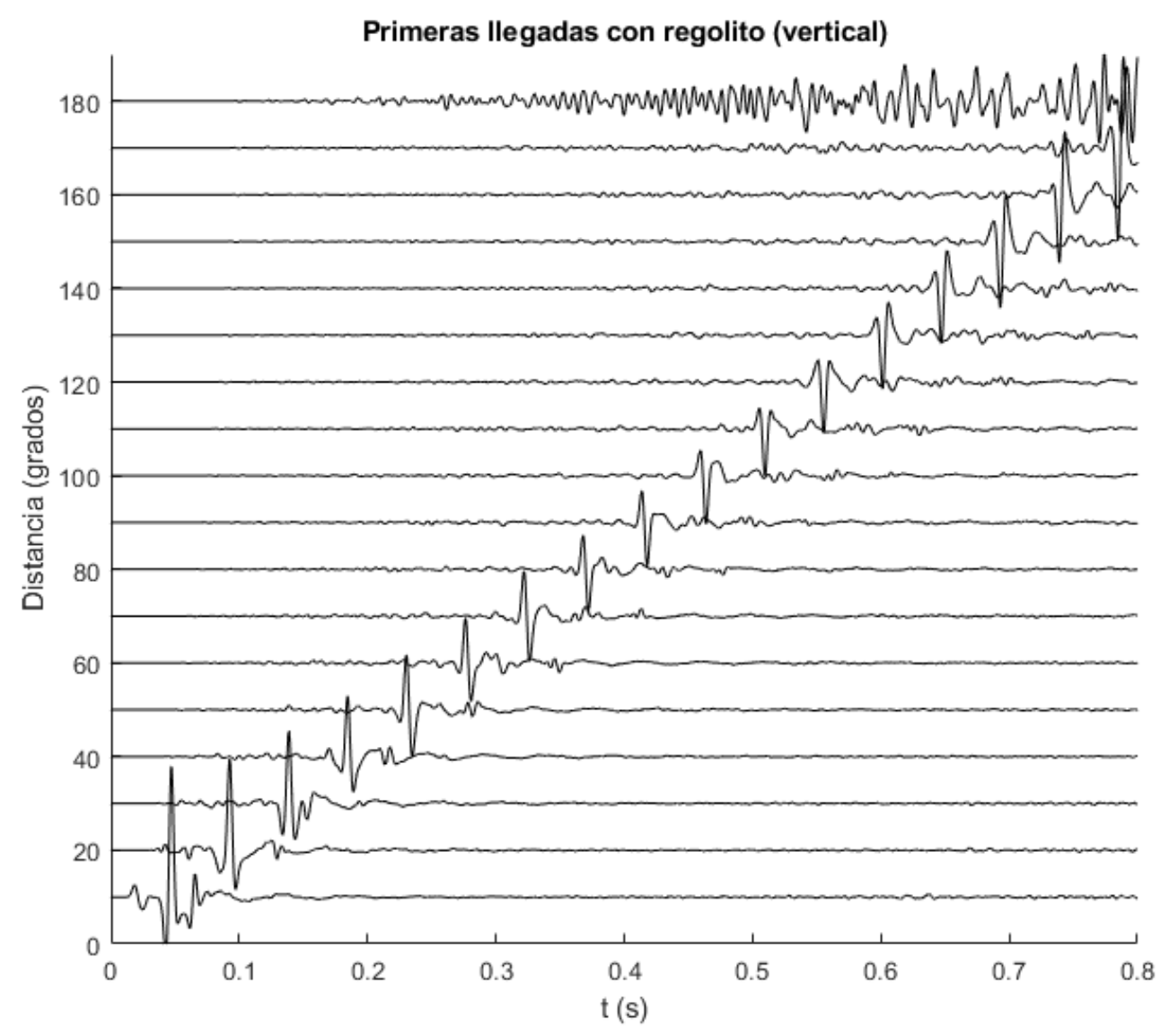

Figura 3.15. Primeras llegadas en el modelo con regolito. La incidencia en la antípoda es vertical y las fases son relativamente más grandes en esta componente.

En este caso particular, la simetría del problema permite que la antípoda registre sucesivas fases recursivas que se reflejan continuamente dentro del regolito (PcP, PcS, $\mathrm{ScP}, \mathrm{ScS})$. Se confina algo de energía de esta manera, pero no es especialmente interesante fuera de un resultado teórico porque en la práctica es más difícil contar con estas condiciones. Lo que se puede esperar ver son las ondas de cuerpo guiadas ya mencionadas, que también forman parte de la energía confinada en el regolito. 


\section{Conclusiones}

\subsection{Valoración general}

Con este trabajo se ha conseguido adaptar una herramienta computacional habitualmente usada en la Tierra a un problema que, en un futuro, esperemos, llegará finalmente a ser una realidad a nivel experimental. El precedente de los impactos ya está asentado en la exploración de asteroides y solo faltaría incluir los experimentos sísmicos dentro de las misiones.

Utilizando dos modelos esféricos muy básicos para las estructuras internas, se han caracterizado algunas propiedades básicas del campo de ondas cuando se considera una corteza de regolito sobre un núcleo más consolidado. La fuente utilizada, pese a ser isótropa, estaba colocada de tal manera que la primera reflexión sobre la superficie conseguía generar ondas $\mathrm{S}$ de reducida amplitud que, de cara a interpretar el campo de ondas, podían considerarse directas (onda S pseudodirecta, en realidad pS).

La duración asignada a la fuente $(100 \mathrm{~Hz})$ ha devuelto sismogramas sintéticos que son continuos desde un punto de vista práctico, pero perfectamente registrables con una frecuencia de muestreo típica en experimentos de sísmica activa $(1000 \mathrm{~Hz})$. El contraste entre amplitudes y cantidad de fases registradas es bien claro, dando una idea de la capacidad que tiene el regolito para concentrar la energía sísmica al atrapar y guiar las ondas. La atenuación no se ha tenido en cuenta, pero se ha asumido que la energía que se proporcionaría al asteroide es suficiente para excitar modos normales y propagar ondas superficiales durante más de una revolución completa.

Se ha evaluado también la posible intervención del campo de ondas como mecanismo geomorfológico en una superficie de regolito sustentada por la propia microgravedad de un asteroide. El campo de ondas generado por la fuente utilizada solo es capaz de superar la aceleración de la gravedad en la antípoda, y sucede cuando las fases Rayleigh recursivas interfieren constructivamente. No obstante, la conclusión final ha sido que de no haber reescalado la magnitud de la fuente a la baja se hubiera podido lograr, con bastante certeza, cumplir las condiciones para levantar polvo en direcciones aleatorias que luego vuelva a depositarse. La hipótesis utilizada es que la fase Rayleigh (la más intensa) tiene que superar instantáneamente la aceleración de la gravedad sin exceder la velocidad de escape, algo plausible teniendo en cuenta los órdenes de magnitud de ambas cantidades y los órdenes de magnitud observados en los sismogramas. Tan solo hacía falta un orden de magnitud adicional en las velocidades y aceleraciones del suelo.

Otra propiedad que se ha asociado al regolito es la capacidad de atrasar los tiempos de llegada de las ondas superficiales, mientras que el núcleo más consolidado propagaría más rápidamente las ondas de cuerpo $\mathrm{P}$ y S. Un resultado de este tipo daría indicaciones de una cierta diferenciación, más o menos pronunciada, en la estructura interna. 


\subsection{Nuevas simulaciones y futuros experimentos}

En este apartado se contemplan cambios o pequeñas modificaciones al modelo para seguir obteniendo datos y los aspectos a tener en cuenta durante un posible experimento sísmico en un asteroide. Esto último podría suceder durante la próxima década.

\subsubsection{El problema de la fuente y la eficiencia sísmica}

El primer paso para producir mejores simulaciones es calcular una fuente a medida. Esta parte del problema se ha dejado fuera del trabajo porque es una parte muy compleja y perfectamente podría ocupar varios artículos. La fuente explosiva ha resultado ser de gran ayuda para generar un campo de ondas interesante pero no es equiparable a conocer bien una fuente ensayada para utilizar en un experimento.

Conocer el patrón de radiación de un impacto en función de ángulo de incidencia sobre la superficie haría posible tener en cuenta el parámetro a la hora de introducir la energía sísmica en el medio. A diferencia de una explosión, un impacto tiene un alto componente direccional que se cuantifica con un par de fuerzas perpendicular y tangencial sobre la superficie. Conocer la cantidad de energía que se llega a introducir al medio permitiría estimar teóricamente las amplitudes esperadas en las distintas estaciones.

El problema energético depende de la eficiencia sísmica del medio (cociente entre la energía liberada en forma de ondas sísmicas y la energía suministrada), que generalmente se soluciona dando un valor típico. Los valores pueden diferir en varios órdenes de magnitud, dependiendo del material y las propiedades del proyectil (masa, velocidad). La fuente explosiva se puede seguir probando, pero asignando magnitudes un orden de magnitud o dos mayores para equipararse mejor a las fuentes utilizadas por Garcia et al., 2015 y Murdoch et al., 2017.

\subsubsection{Atenuación (factor de calidad)}

La atenuación se puede tener en cuenta probando con distintos valores del factor de calidad. Para probar con valores bajos lo mejor sería simular hasta la primera llegada de ondas Rayleigh (R1), ya que la amplitud en estos casos tiende a caer rápido (Garcia et al., 2015). Para valores más altos la atenuación es mucho más lenta y deja de ser relevante en las escalas temporales que se manejarían durante estos experimentos. Si se asume un factor de calidad bueno (asteroide bastante elástico) se puede ignorar completamente teniendo en cuenta lo dicho.

Se debe tener en cuenta que la atenuación depende del medio de propagación, que es notablemente distinto al pasar del regolito al núcleo. Es razonable pensar que el regolito es mucho más atenuante que las estructuras subyacentes, algo que se manifestaría con una razón de amplitudes entre las ondas Rayleigh y las ondas de cuerpo más baja. En 
estas condiciones, el campo de ondas presentaría un aspecto diferente en una simulación larga. Habría menos energía elástica confinada en el regolito de la que hay al asumir que todo el modelo es elástico.

\subsubsection{Cambios en el modelo de fondo}

Para introducir modificaciones al modelo no solo basta con cambiar el tamaño de las capas y los parámetros correspondientes. Hay que tener en cuenta también la frecuencia central del pulso que se está introduciendo. La resolución vertical que se pueda garantizar en un experimento está determinada por la frecuencia de las ondas que se registran. En los casos propuestos en este trabajo se ha comprobado que un pulso centrado en $100 \mathrm{~Hz}$ puede resolver la capa de regolito al ser $\lambda_{\mathrm{p}}=9 \mathrm{~m}$ la longitud de las ondas $\mathrm{P}$ (las más rápidas), porque la resolución vertical es $\lambda / 4=2,25 \mathrm{~m}$ (mínima distancia para poder distinguir reflectores sin que se junten en los registros). El tamaño del asteroide nunca va a ser problemático porque en principio estos experimentos solo hacen falta si se quiere acceder bien al interior de un asteroide que tiene ya un cierto diámetro.

Por ejemplo, si se redijese el espesor de la capa de regolito a $5 \mathrm{~m}$ se podría seguir resolviendo, pero también podría ser conveniente reescalar la duración de la fuente reduciéndola a la mitad (pulso de $200 \mathrm{~Hz}$ ). En este caso $\lambda_{\mathrm{p}}=4,5 \mathrm{~m}$ y se compensaría el cambio del espesor. Una fuente de esta duración también era una opción plausible (Murdoch et al., 2017) y hubiera producido mayores amplitudes. En combinación con un regolito más fino, tal vez hubiese sido suficiente para superar la aceleración de la gravedad a lo largo del recorrido de la onda superficial para conseguir una ola de polvo.

Un resultado interesante podría ser ver cómo cambia el espectro de los sismogramas en función de la anchura del regolito para fuentes de la misma magnitud y duración.

Se asume en todo momento que los instrumentos son capaces de muestrear con la frecuencia adecuada para recuperar, como mínimo, una parte razonable del espectro de la señal. Si se utilizan pulsos de $200 \mathrm{~Hz}$, una frecuencia de muestreo de $500 \mathrm{~Hz}$ podría quedarse corta para registrar oscilaciones de corto periodo. Esto es igualmente importante cuando no se conoce la frecuencia central de la fuente. Con $500 \mathrm{~Hz}$ la frecuencia más alta que se va a muestrear son $250 \mathrm{~Hz}$, que equivale a $\lambda_{\mathrm{p}}=3,6 \mathrm{~m}$ en el regolito de los modelos. La frecuencia de muestreo también puede llegar a limitar la resolución si el pulso está centrado en una frecuencia por encima de la máxima recuperable.

\subsubsection{Heterogeneidades y topografía}

Añadir heterogeneidades aleatorias al modelo es una forma de complicarlo más y asemejarlo a algo que podría verse en un experimento real. El método más sencillo consiste en introducir reflectores finitos (esféricos) o simplemente puntuales. Axisem cuenta con una herramienta para añadir heterogeneidades, pero en la última versión del 
manual los desarrolladores destacan que está todavía en desarrollo y no está testada al mismo nivel que lo está el código sin incluir esta herramienta.

Considerar una topografía y forma cualesquiera supondría utilizar un modelo completamente tridimensional y resolver el problema numérico en 3D. La complejidad y coste computacional del método aumentan al añadir la tercera dimensión al método numérico. Esto es algo que escapa completamente al método numérico de Axisem, que precisamente ignora la topografía para poder resolver un modelo $2 \mathrm{D}$ y calcular analíticamente la tercera dimensión. Haría falta entonces cambiar completamente de herramienta.

\subsubsection{Colocación del instrumento}

Los tiempos de llegada en una estación alejada del impacto son importantes para caracterizar la estructura interna del asteroide. En los modelos aquí contemplados, las llegadas a la antípoda de las ondas de cuerpo $\mathrm{P}$ y $\mathrm{S}$ directas son prácticamente las mismas incluso con la presencia del regolito. Sin embargo, la onda superficial presenta un tiempo de llegada mucho más lento al que se espera en un medio homogéneo cuando existe una capa de regolito con espesor suficiente y menos consolidada que el interior.

Una estación situada cerca de la fuente, sin llegar a poner en peligro el instrumento, puede registrar tanto ondas $\mathrm{P}$ y $\mathrm{S}$ directas como reflexiones y refracciones que se han producido cerca de la superficie. Sería esta la manera ideal de caracterizar las velocidades sísmicas en el regolito sin tener que buscar ondas de cuerpo guiadas que se han mezclado con otras fases en un registro más alejado. Las ondas superficiales tienen trayectorias conocidas, son más intensas y se sabe que viajan únicamente por la superficie, por lo que se distinguen bien en cualquier estación.

Si se contase únicamente con una estación, lo conveniente sería situarla lejos de la fuente para que las ondas de cuerpo proporcionen información del interior y las superficiales de la superficie, tratando de distinguir además las ondas de cuerpo que han sido guiadas por la superficie. Se puede asumir también que una misión que incluya la sísmica en su paquete de instrumentos contará con otras herramientas para analizar la superficie. En ese caso se puede utilizar la sísmica para acceder mejor al interior.

Por último, algo que no se ha mencionado explícitamente hasta ahora, pero es de sentido común, es que el uso de ondas sísmicas para levantar polvo y modificar la superficie del asteroide es algo que se plantea teóricamente para evaluar los posibles efectos de un impacto natural. Es un resultado muy bonito a nivel de simulación, pero no tendría ningún sentido intentar reproducirlo si se pretenden obtener registros sísmicos. El acoplo de los instrumentos con la superficie ya sería bastante pobre de por sí, y una fuente demasiado intensa puede levantarlos e inutilizarlos. Una fuente como la utilizada en este trabajo sería ideal para sondear un asteroide de un tamaño similar al aquí considerado. Si no se colocan instrumentos en la superficie, se pueden tomar imágenes del asteroide en los instantes posteriores al impacto para identificar una posible respuesta sísmica del medio. 


\section{Referencias}

Adams, E., Oshaughnessy, D., Reinhart, M., John, J., Congdon, E., Gallagher, D., Abel, E., Atchison, J., Fletcher, Z., Chen, M., Heistand, C., Huang, P., Smith, E., Sibol, D., Bekker, D., Carrelli, D., 2019. Double Asteroid Redirection Test: The Earth Strikes Back. pp. 111. https://doi.org/10.1109/AERO.2019.8742007

Cecilia, J., 2019. Mining the moon ready to lift off by 2025. MINING.COM. URL https://www.mining.com/mining-moon-ready-lift-off-2025/ (accessed 9.2.20).

Chaljub, E., Komatitsch, D., Vilotte, J.-P., Capdeville, Y., Valette, B., Festa, G., 2007. Spectralelement analysis in seismology, in: Wu, R.-S., Maupin, V., Dmowska, R. (Eds.), Advances in Geophysics, Advances in Wave Propagation in Heterogenous Earth. Elsevier, pp. 365-419. https://doi.org/10.1016/S0065-2687(06)48007-9

Chapman, C.R., 2004. The hazard of near-Earth asteroid impacts on earth. Earth Planet. Sci. Lett. 222, 1-15. https://doi.org/10.1016/j.epsl.2004.03.004

Cheng, A.F., Michel, P., Reed, C., Galvez, A., Carnelli, I., 2012. DART: Double Asteroid Redirection Test 2.

Cheng, A.F., Rivkin, A.S., Michel, P., Atchison, J., Barnouin, O., Benner, L., Chabot, N.L., Ernst, C., Fahnestock, E.G., Kueppers, M., Pravec, P., Rainey, E., Richardson, D.C., Stickle, A.M., Thomas, C., 2018. AIDA DART asteroid deflection test: Planetary defense and science objectives. Planet. Space Sci. 157, 104-115. https://doi.org/10.1016/j.pss.2018.02.015

Cooper, M.R., Kovach, R.L., Watkins, J.S., 1974. Lunar near-surface structure. Rev. Geophys. 12, 291-308. https://doi.org/10.1029/RG012i003p00291

Garcia, R., Murdoch, N., Mimoun, D., 2015. Micro-meteoroid seismic uplift and regolith concentration on kilometric scale asteroids. https://doi.org/10.1016/j.icarus.2015.02.014

Gardner, G.H.F., Gardner, L.W., Gregory, A.R., 1974. Formation velocity and density-the diagnostic basics for stratigraphic traps. GEOPHYSICS 39, 770-780. https://doi.org/10.1190/1.1440465

Lognonné, P., Banerdt, W.B., Giardini, D., Pike, W.T., Christensen, U., Laudet, P., de Raucourt, S., Zweifel, P., Calcutt, S., Bierwirth, M., Hurst, K.J., ljpelaan, F., Umland, J.W., LlorcaCejudo, R., Larson, S.A., Garcia, R.F., Kedar, S., Knapmeyer-Endrun, B., Mimoun, D., Mocquet, A., Panning, M.P., Weber, R.C., Sylvestre-Baron, A., Pont, G., Verdier, N., Kerjean, L., Facto, L.J., Gharakanian, V., Feldman, J.E., Hoffman, T.L., Klein, D.B., Klein, K., Onufer, N.P., Paredes-Garcia, J., Petkov, M.P., Willis, J.R., Smrekar, S.E., Drilleau, M., Gabsi, T., Nebut, T., Robert, O., Tillier, S., Moreau, C., Parise, M., Aveni, G., Ben Charef, S., Bennour, Y., Camus, T., Dandonneau, P.A., Desfoux, C., Lecomte, B., Pot, O., Revuz, P., Mance, D., tenPierick, J., Bowles, N.E., Charalambous, C., Delahunty, A.K., Hurley, J., Irshad, R., Liu, H., Mukherjee, A.G., Standley, I.M., Stott, A.E., Temple, J., Warren, T., Eberhardt, M., Kramer, A., Kühne, W., Miettinen, E.-P., Monecke, M., Aicardi, C., André, M., Baroukh, J., Borrien, A., Bouisset, A., Boutte, P., Brethomé, K., Brysbaert, C., Carlier, T., Deleuze, M., Desmarres, J.M., Dilhan, D., Doucet, C., Faye, D., Faye-Refalo, N., Gonzalez, R., Imbert, C., Larigauderie, C., Locatelli, E., Luno, L., Meyer, J.-R., Mialhe, F., Mouret, J.M., Nonon, M., Pahn, Y., Paillet, A., Pasquier, P., Perez, G., Perez, R., Perrin, L., Pouilloux, B., Rosak, A., Savin de Larclause, I., Sicre, J., Sodki, M., Toulemont, N., Vella, B., Yana, C., Alibay, F., Avalos, O.M., Balzer, M.A., Bhandari, P., Blanco, E., Bone, B.D., Bousman, J.C., Bruneau, P., Calef, F.J., Calvet, R.J., D'Agostino, S.A., de los Santos, G., Deen, R.G., Denise, R.W., Ervin, J., Ferraro, N.W., Gengl, H.E., Grinblat, F., Hernandez, D., Hetzel, M., Johnson, M.E., Khachikyan, L., Lin, J.Y., Madzunkov, S.M., Marshall, S.L., Mikellides, I.G., Miller, E.A., Raff, W., Singer, J.E., Sunday, C.M., 
Villalvazo, J.F., Wallace, M.C., Banfield, D., Rodriguez-Manfredi, J.A., Russell, C.T., Trebi-Ollennu, A., Maki, J.N., Beucler, E., Böse, M., Bonjour, C., Berenguer, J.L., Ceylan, S., Clinton, J., Conejero, V., Daubar, I., Dehant, V., Delage, P., Euchner, F., Estève, I., Fayon, L., Ferraioli, L., Johnson, C.L., Gagnepain-Beyneix, J., Golombek, M., Khan, A., Kawamura, T., Kenda, B., Labrot, P., Murdoch, N., Pardo, C., Perrin, C., Pou, L., Sauron, A., Savoie, D., Stähler, S., Stutzmann, E., Teanby, N.A., Tromp, J., van Driel, M., Wieczorek, M., Widmer-Schnidrig, R., Wookey, J., 2019. SEIS: Insight's Seismic Experiment for Internal Structure of Mars. Space Sci. Rev. 215, 12. https://doi.org/10.1007/s11214-018-0574-6

Martin, R., Komatitsch, D., Blitz, C., Le Goff, N., 2008. Simulation of Seismic Wave Propagation in an Asteroid Based upon an Unstructured MPI Spectral-Element Method: Blocking and Non-blocking Communication Strategies, in: Palma, J.M.L.M., Amestoy, P.R., Daydé, M., Mattoso, M., Lopes, J.C. (Eds.), High Performance Computing for Computational Science - VECPAR 2008, Lecture Notes in Computer Science. Springer, Berlin, Heidelberg, pp. 350-363. https://doi.org/10.1007/978-3-540-92859-1_32

Murdoch, N., Hempel, S., Pou, L., Cadu, A., Garcia, R.F., Mimoun, D., Margerin, L., Karatekin, O., 2017. Probing the internal structure of the asteriod Didymoon with a passive seismic investigation. Planet. Space Sci. 144. https://doi.org/10.1016/j.pss.2017.05.005

Nissen-Meyer, T., Driel, M., Stähler, S., Hosseini, K., Hempel, S., Auer, L., Colombi, A., Fournier, A., 2014. AxiSEM: Broadband 3-D seismic wavefields in axisymmetric media. Solid Earth 5, 425-445. https://doi.org/10.5194/se-5-425-2014

Nunn, C., Garcia, R.F., Nakamura, Y., Marusiak, A.G., Kawamura, T., Sun, D., Margerin, L., Weber, R., Drilleau, M., Wieczorek, M.A., Khan, A., Rivoldini, A., Lognonné, P., Zhu, P., 2020. Lunar Seismology: A Data and Instrumentation Review. Space Sci. Rev. 216, 89. https://doi.org/10.1007/s11214-020-00709-3

Quillen, A.C., Zhao, Y., Chen, Y., Sánchez, P., Nelson, R.C., Schwartz, S.R., 2019. Impact excitation of a seismic pulse and vibrational normal modes on asteroid Bennu and associated slumping of regolith. Icarus 319, 312-333. https://doi.org/10.1016/j.icarus.2018.09.032

Rumpf, C.M., Lewis, H.G., Atkinson, P.M., 2017. Asteroid impact effects and their immediate hazards for human populations. Geophys. Res. Lett. 44, 3433-3440. https://doi.org/10.1002/2017GL073191

"The Hayabusa Missions" with Seiji Sugita, University of Tokyo, Japan - ISSI, n.d. URL https://www.issibern.ch/index.php/2020/07/30/hayabusa_missions/ (accessed 9.2.20).

Walker, J.D., Huebner, W.F., 2004. Loading sources for seismological investigations of nearEarth objects. Adv. Space Res., The Impact of Minor Bodies of Our Solar System on Planets and Their Middle and Upper Atmosphere 33, 1564-1569. https://doi.org/10.1016/S0273-1177(03)00454-X

Walsh, K., 2018. Rubble Pile Asteroids. Annu. Rev. Astron. Astrophys. 56. https://doi.org/10.1146/annurev-astro-081817-052013

Yang, X., Stump, B.W., Pearson, D.C., 1999. Moment tensor inversion of single-hole mining cast blasts. Geophys. J. Int. 139, 679-690. https://doi.org/10.1046/j.1365246x.1999.00958.x

Zacny, K., Chu, P., Craft, J., Cohen, M., James, W., Hilscher, B., 2013. Asteroid Mining. Presented at the AIAA SPACE 2013 Conference and Exposition. https://doi.org/10.2514/6.2013-5304 